\title{
THE SOCIAL IMPACT OF INSTITUTION SOME AGRICULTURAL PROJECTS BY ENCROACHMENT ON AGRICULTURAL LAND IN GHARBIA GOVERNORATE
}

\author{
BADR , OMAR AHMAD , M. S. A. GHAZI and \\ EMAN RAMZY EL-FAHL
}

Agric. Econ. Res. Instit., ARC, Giza

(Manuscript received 30 January 2017)

\begin{abstract}
$\mathrm{T}$ he problem of the encroachment on agricultural land is the one of biggest problems in Egypt in the period (2011-2014) where it reached about 981 thousand Feddan in the Republic which led to lower gross national product of agricultural crops and the impact of food security, which need to procedure this research to know economic and social impacts associated with this phenomenon, by using preliminary data obtained from those built on the land for agricultural entrepreneurs, including: the owners of poultry farms projects and owners of projects fattening cattle, the results are as follows:
\end{abstract}

\section{First: For owners of poultry projects:}

Most of the owners of poultry projects focus due to encroachment on agricultural land for the establishment of poultry farms projects are illiterate rate of $31.53 \%$ and farmers increased by $44.83 \%$, has been working in agriculture, were found to be the main reasons for the establishment of projects are: fit place for the type of project, ease of product distribution reaching their respective proportion of $62 \%$ of the total number of sample duplicates and more beneficiaries of the project are concentrated in two categories: medium and low-income increased by $72.42 \%$ of the total beneficiaries of fattening farms and poultry farms producing eggs.

\section{Second: For owners of fattening cattle projects:}

Most business owners focus as a result of encroachment on agricultural land for cattle fattening farm projects: Mom, reads and writes, and a increased by $82.36 \%$ of the total entrepreneurs who are farmers, and that the main reasons for the establishment of projects are: fit place for the type of project, and the abundance of raw materials, The biggest beneficiaries of the project are concentrated in two categories: limited and average income increased by $88.24 \%$ of the total beneficiaries, has been shown from the views of entrepreneurs to establish the project did not affect the price of the item up and down, as it turns out that fattening cattle projects owners who are on the aware of the national economic effects which limited their drawbacks in both: damage to agricultural output, raise food prices in Egypt and depriving individuals of food, representing, and the most important problems they face are concentrated in: fear of removal, the fear of law enforcement. respectively and work. In addition to propose some Scenarios or alternatives plane to the cultivation of acres of agricultural land Gharbia Governorate show that the top of this Scenarios was to cultivate wheat and tomatoes alternately with net yield per Fadden it reached 18.272 thousand L.E per Feddan. 


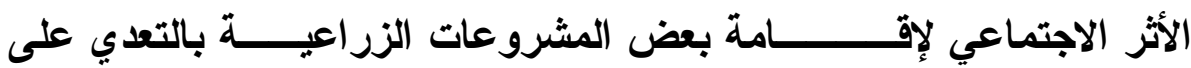 الأر اضي الزراعيــة بمحافظة الغربية}

عمر أحمد بلر ، محمد سيد أحمد غازي ، إيمان رمزي الفحل

قسم بحوث الدراسات الإقليمية - معهز بحوث الاقتصاد الزراعي - مركز البحوث الزراعبة

\section{المقدمة}

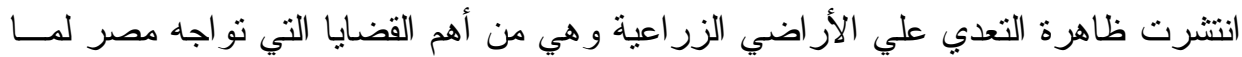

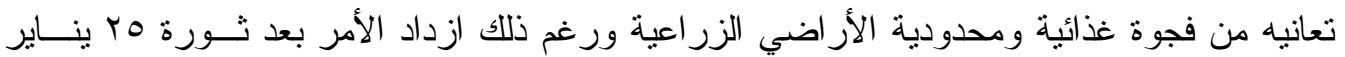

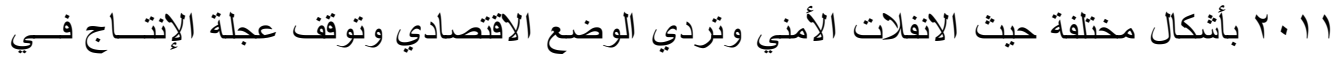

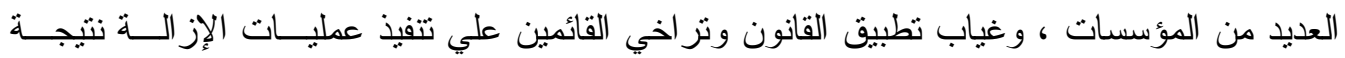

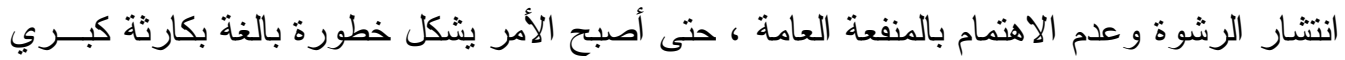

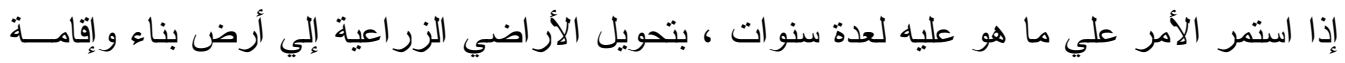

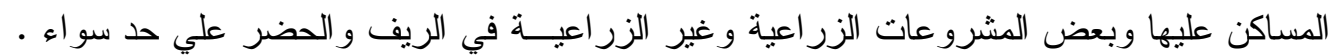

\section{مشكلة البحث}

بلغ حجم التعدي علي الأراضي الزر اعية نحو اوه ألف فدان من أجود الأراضي الزراعية

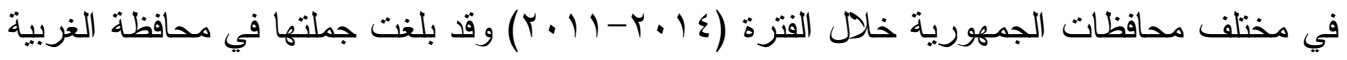

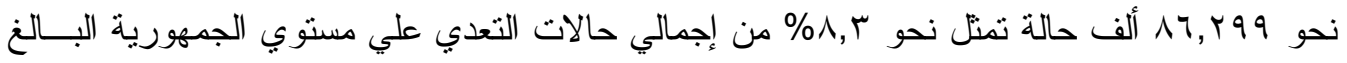

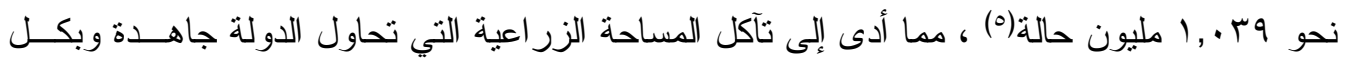
السبل زيادتها عن طريق استصلاح الأراضي في المناطق الصحر اوية وهو ما يعرف بالتوسع الأفقي

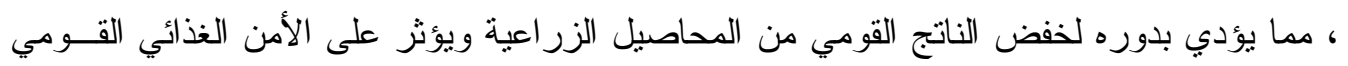

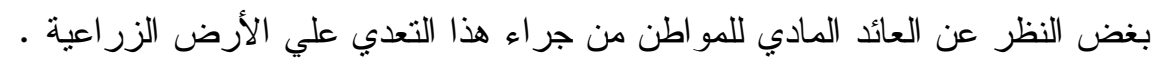

\section{هاف البحث}

يهدف البحث التعرف علي بعض الآثار الاجتماعيــة والاقتصـــادية الناتجــة عـن إقامـــة

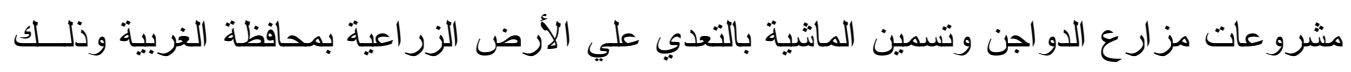

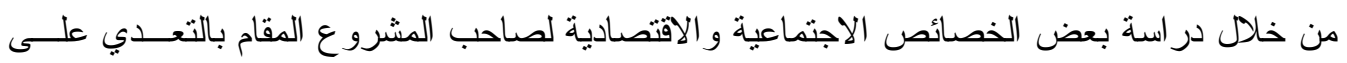

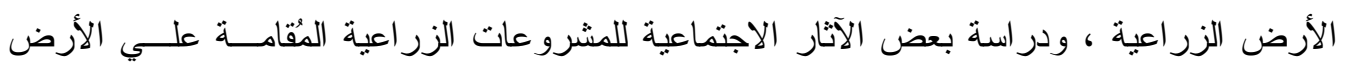

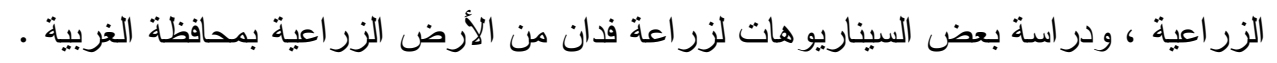

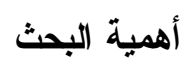

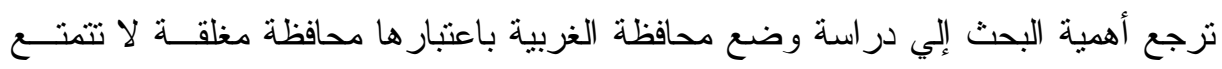

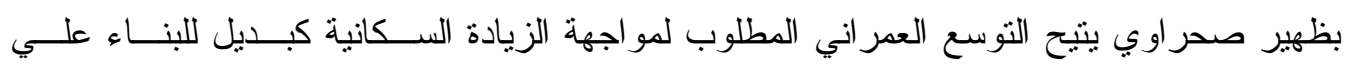

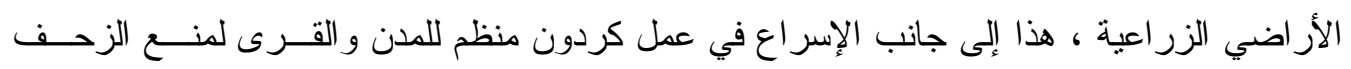

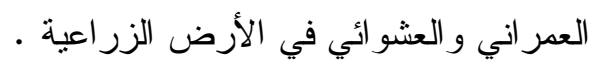




\section{الأسلوب البحثي ومصادر البيانات}

اعتمد البحث على أسلوب التحليل الوصفي بالإضافة إلى استخدام بعض الأدوات الإحصائية

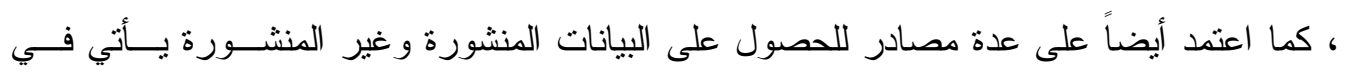

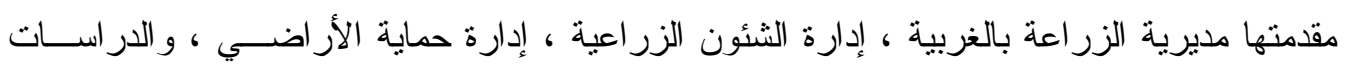

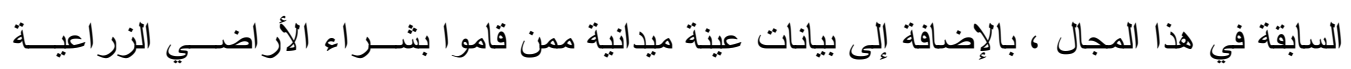

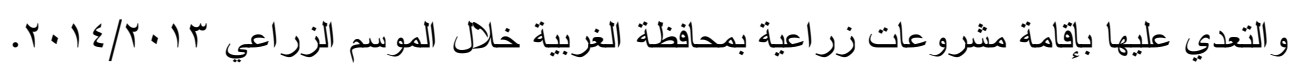

\section{عينة الار اسة الميداتية}

نظراً لعدم وجود إطار دقيق لحالات التعدي علي مستوي قري مر اكز المحافظة ، تم تقسيم

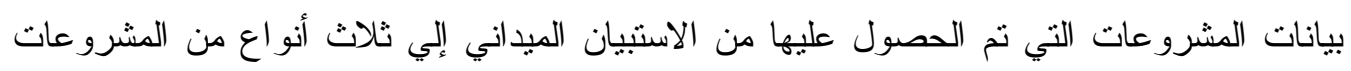
وهي : مئر

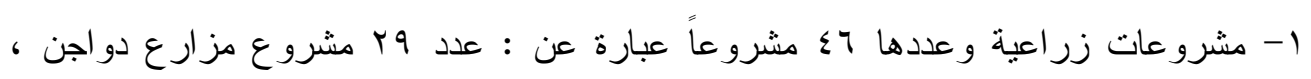

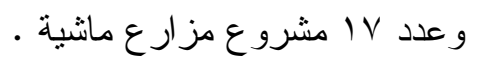

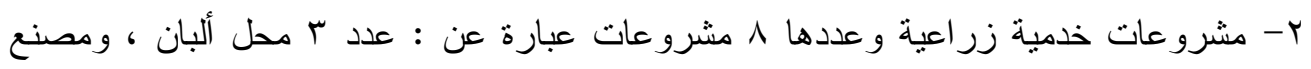

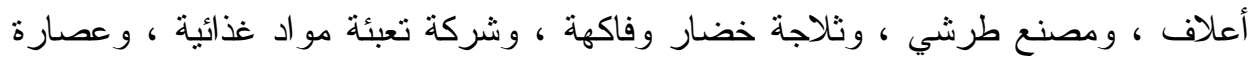
قصب .

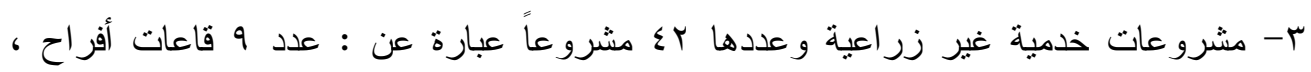

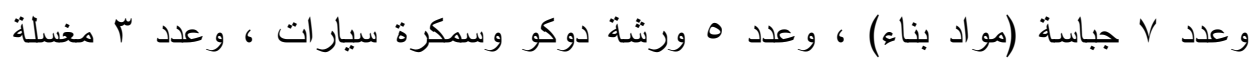

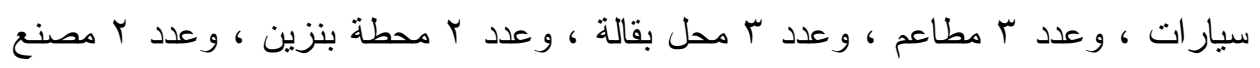

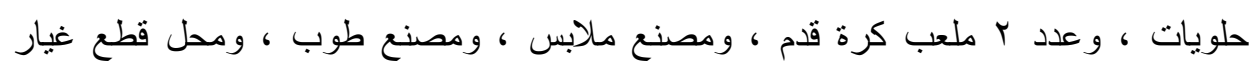

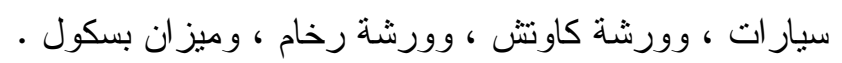

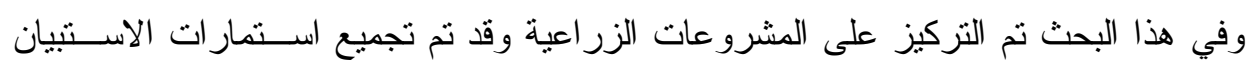

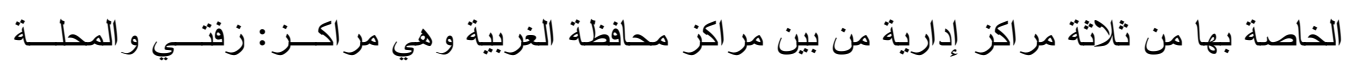

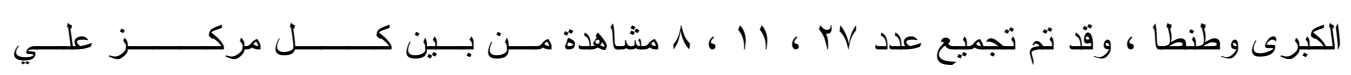

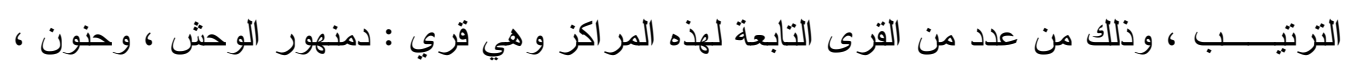

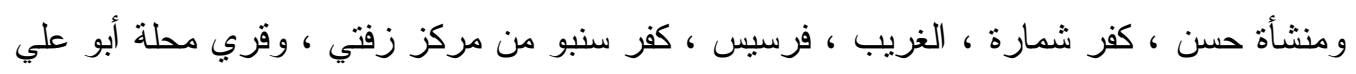

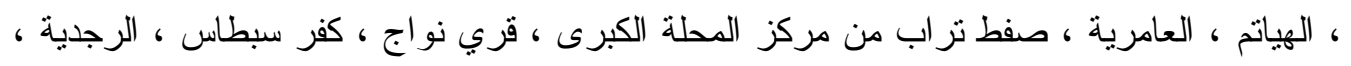

سبرباي من مركز طنطا.

\section{النتائج و المناقشات}

الأهمية النسبية لحالات التعدي بالبناء على الأراضي الزراعية:

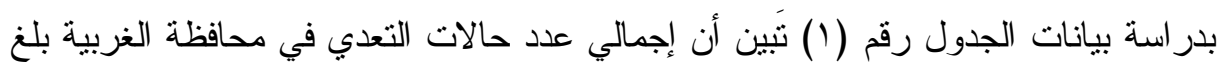

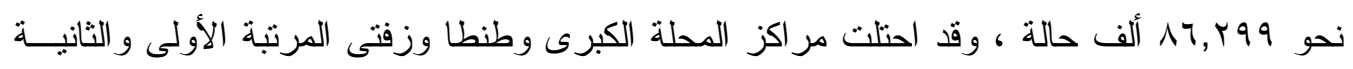

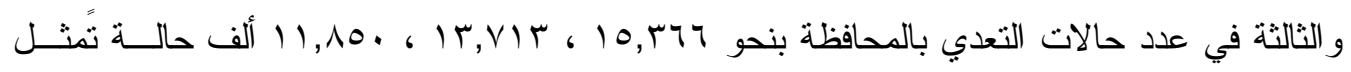

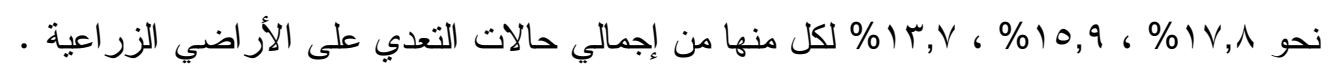


جدول رقم (1): أعداد حالات التعدي و المساحات المتعدى عليها من الأراضي الزر اعية بالفدان

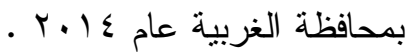

\begin{tabular}{|c|c|c|c|c|c|}
\hline \multicolumn{4}{|c|}{ إجمالي المساحات المتعدي عليها } & \multirow{2}{*}{ 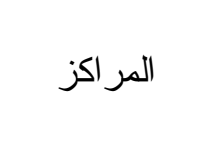 } & \multirow{2}{*}{ s } \\
\hline$\%$ & المساحة الكلية & $\%$ & عدد حالات & & \\
\hline $17, V$ & TVV & 10,9 & ITVIT & طنطا & 1 \\
\hline$r \cdot, V$ & NTV & $I V, \Lambda$ & 10474 & المحلة الكبرى & r \\
\hline $1 \cdot, \varepsilon$ & $\{r \mid$ & $11, \varepsilon$ & $9 \wedge \ldots$ & كفر الزيات & $r$ \\
\hline $17, \varepsilon$ & ז & $I T, V$ & 1110. & زفتى & $\varepsilon$ \\
\hline $1 \cdot, 1$ & $\varepsilon r \varepsilon$ & $1 \cdot, r$ & AVTr & السنطة & 0 \\
\hline$\wedge, \nearrow$ & $r \leqslant \Lambda$ & $1 \cdot, \wedge$ & 9फा1 & قطور & 7 \\
\hline$V, r$ & $r \cdot T$ & $\wedge, \varepsilon$ & VYAT & بسيون & v \\
\hline$\wedge, q$ & roq & 11,1 & $1 \cdot r \cdot r$ & سمنود & $\wedge$ \\
\hline $1 \ldots$ & $\varepsilon \cdot \varepsilon \varepsilon$ & $1 \ldots$ & 人тr৭q & لإجمالي & \\
\hline
\end{tabular}

المصدر: مديرية الزراعة بالغربية ، الثئون الزراعية ، سجلات إدارة الإحصاءات الزراعية ، بيانات غير منشورة .

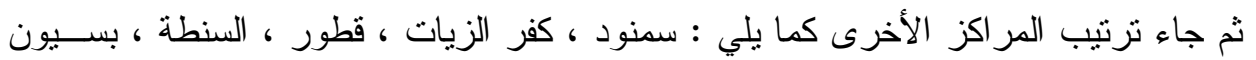

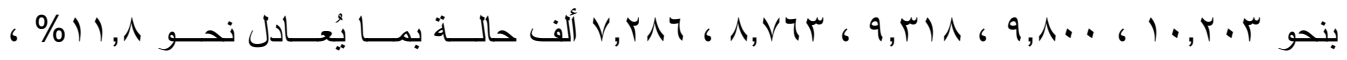

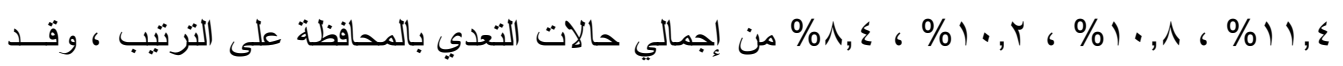

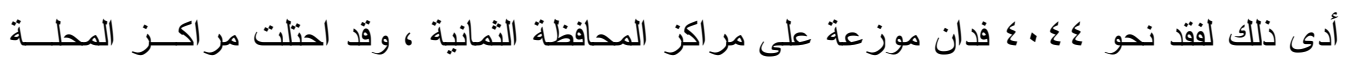

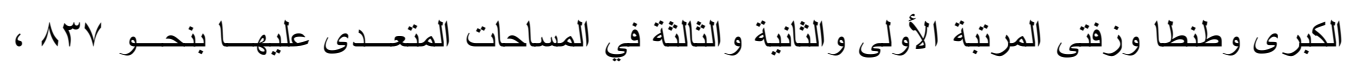

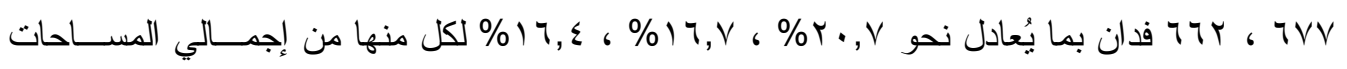

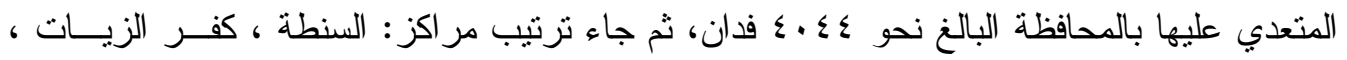

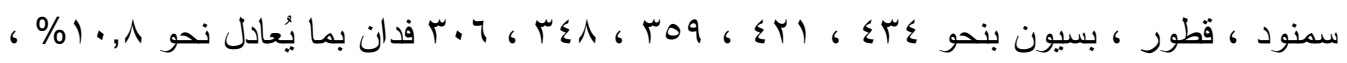

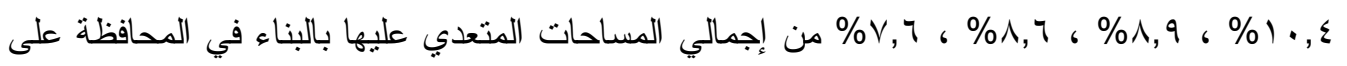

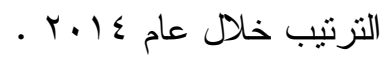
تصنيف عينة البحث : تم تقسيم بيانات الاستبيان الميداني وفقاً للمشروعات الإنتاجية الزر اعية وعددها بـ؛ مشــروعاً

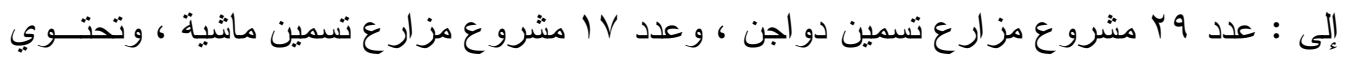

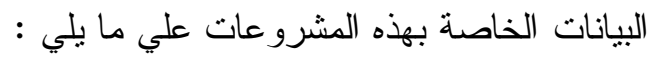

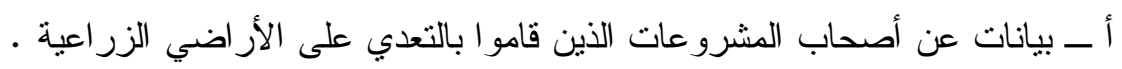

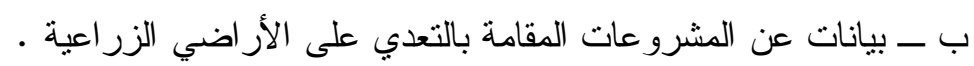


وقد أوضحت بيانات الجدول رقم (r) أن المشروعات الزر اعية بلغت نحــو بـ مشــروعاً

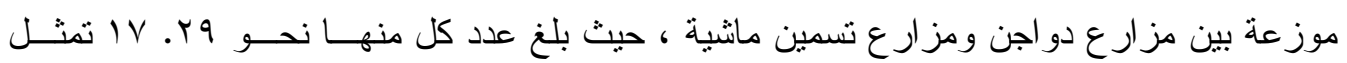

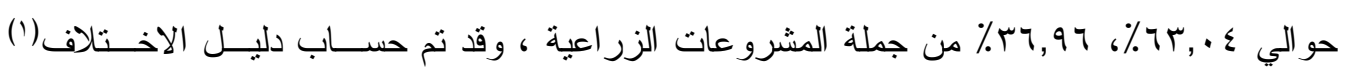

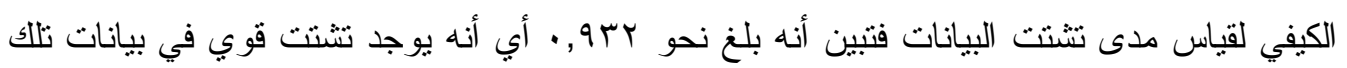

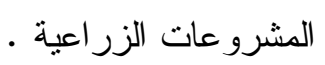
جدول رقم (r): الأهمية النسبية لعدد المشروعات الزر اعية في عينة الدر اسة

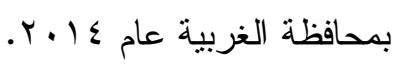

\begin{tabular}{|c|c|c|c|}
\hline دليل الاختلاف الكيفي & \% من الإجمالي العام & 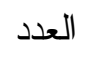 & المشرو عات \\
\hline \multirow{3}{*}{ 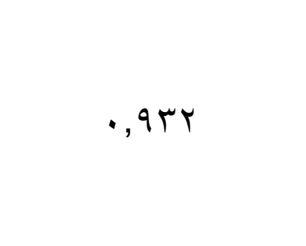 } & $\pi$ & rq & مز ارع دو اجن \\
\hline & $r 7,97$ & iv & حظائر مانثية \\
\hline & $1 \cdots$ & $\varepsilon 7$ & الإجمالي \\
\hline
\end{tabular}

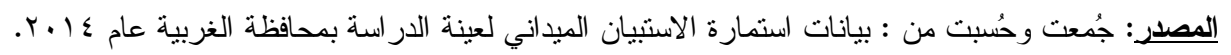

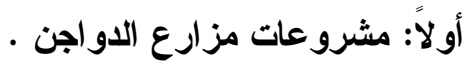

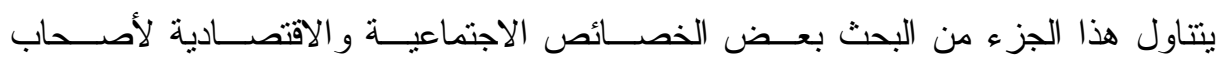

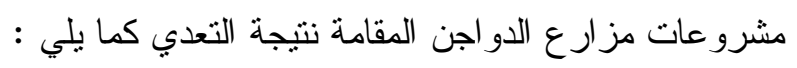

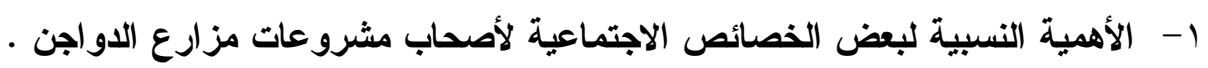

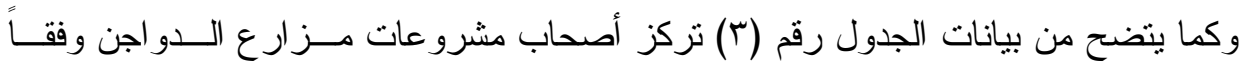

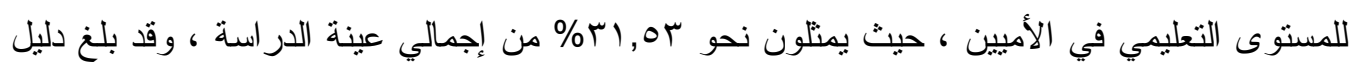

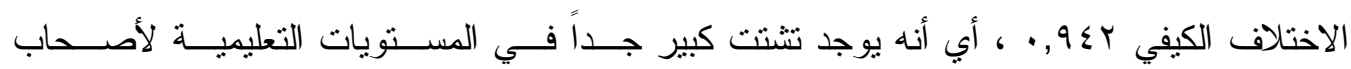

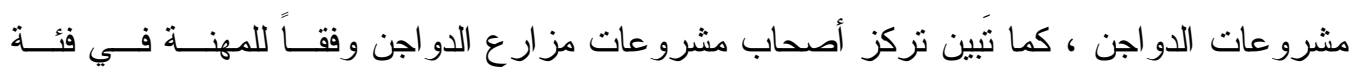

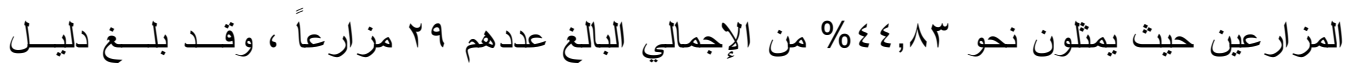

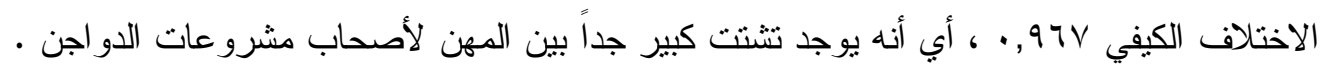


جدول رقم (ץ): الأهية النسبية لبعض الخصائص الاجتماعية لأصحاب مشروعات مزارع الدواجن في عينة الدراسة بمحافظة الغربية عام ع ( ب.

\begin{tabular}{|c|c|c|c|c|c|}
\hline \multicolumn{3}{|c|}{ المؤشر ات الإحصائية لأصحاب مشروعات مز ارع الدو اجن } & \multicolumn{2}{|c|}{ 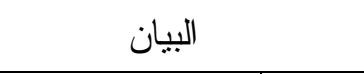 } & م \\
\hline دليل الاختلاف الكيفي & $\%$ & العدد = & & \multirow{6}{*}{$\begin{array}{c}\bar{y} \\
\text { 㝵 } \\
\text { y } \\
\text { 可 } \\
\text { 多: }\end{array}$} & \\
\hline \multirow{5}{*}{$\cdot, 9 \leq r$} & r, & 9 & أمي & & 1 \\
\hline & $1 r, v q$ & $\varepsilon$ & يقر أ ويكتب & & r \\
\hline & 7,9 . & r & تعليم أساسي & & r \\
\hline & r & 9 & مؤ هل متوسط & & $\varepsilon$ \\
\hline & $I V, Y \leq$ & 0 & مؤ هل جامعي & & 。 \\
\hline \multirow{3}{*}{$\cdot, 97 \mathrm{~V}$} & $\varepsilon \varepsilon, \wedge r$ & ir & مز ارع & \multirow{3}{*}{$\bar{P}$} & 1 \\
\hline & $r \varepsilon, 1 \leqslant$ & $v$ & موظف & & r \\
\hline & r, & 9 & أعمال حرة & & r \\
\hline
\end{tabular}

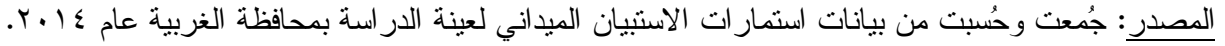

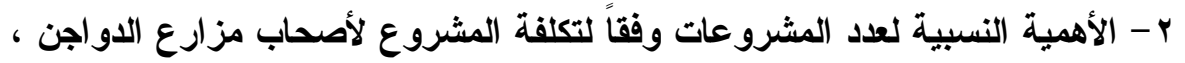

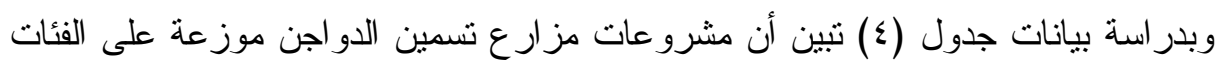

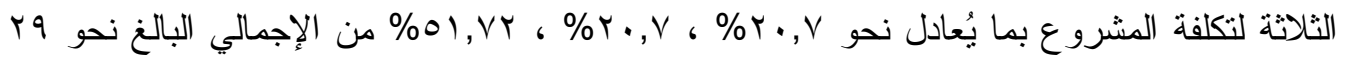

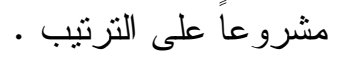
جدول رقم (ع): الأهمية النسبية لعدد المشروعات وفقاً لتكلفة المشروع لدي أصحاب مشروعات الدو اجن في عينة الدر اسة بمحافظة الغربية عام ع ا ـ r.

\begin{tabular}{|c|c|c|c|c|c|c|c|c|c|}
\hline \multicolumn{2}{|c|}{ الإجمالي } & \multicolumn{6}{|c|}{ فئات المشرو عات } & \multirow{3}{*}{ نوع المشروع } & \multirow{3}{*}{ r } \\
\hline \multirow{2}{*}{ 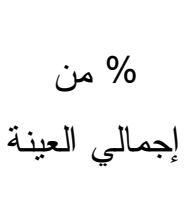 } & \multirow{2}{*}{ الجمالي عدد المشروعا } & \multicolumn{2}{|c|}{ • . . ألف جنيه } & \multicolumn{2}{|c|}{ ألف جنيه > } & \multicolumn{2}{|c|}{ ألف من جن ألف } & & \\
\hline & & $\%$ & العد & $\%$ & العد & $\%$ & العد & & \\
\hline $94,1$. & TV & $01, V T$ & 10 & $r \cdot, V$ & 7 & $r \cdot, V$ & 7 & مز ارع تسمين & 1 \\
\hline $7,9$. & r & $r, \varepsilon 0$ & 1 & . & . & $r, \leqslant 0$ & 1 & مز ارع إنتاج & r \\
\hline & & \multicolumn{2}{|c|}{ ש } & \multicolumn{2}{|c|}{ صفر } & \multicolumn{2}{|c|}{$\cdot, \leqslant q}$. & \multicolumn{2}{|c|}{ دليل الاختلاف } \\
\hline $1 \ldots$ & rq & $00,1 V$ & 17 & $r \cdot, V$ & 7 & $r \varepsilon, 1 \leqslant$ & V & الإجمالي & \\
\hline
\end{tabular}

المصدر: جُمعت وحُسبت من بيانات استمار ات الاستبيان الميداني لعينة الدراسة .

كما تبيَن أيضاً أن مشروعات مز ارع إنتاج البيض موزعة على الفئـات الثلاثــة الخاصـــة

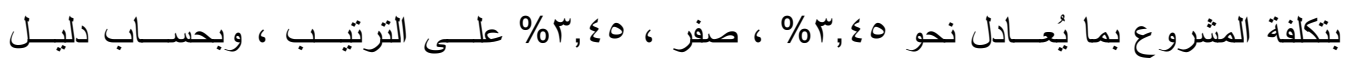




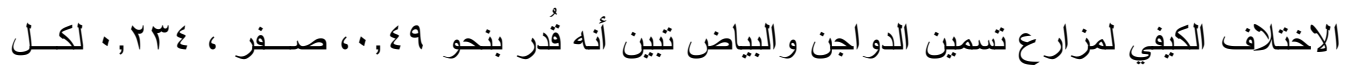

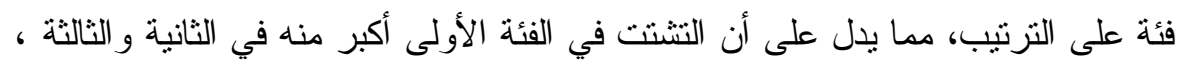

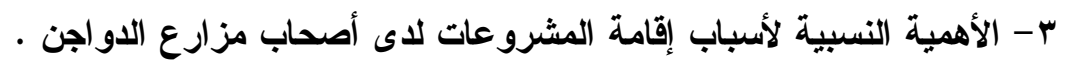

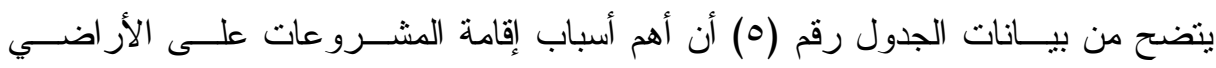

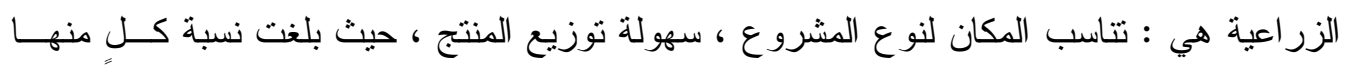

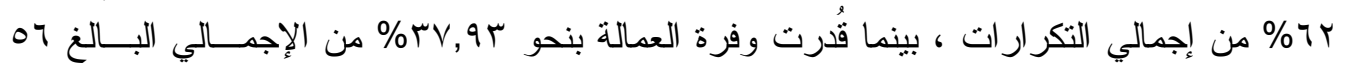
تكراراً جدول رقم (0): الأهمية النسبية لأسباب إقامة المشروعات لدي أصحاب مشروعات الدواجن في

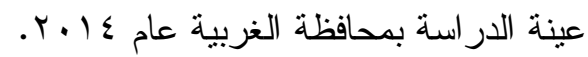

\begin{tabular}{|c|c|c|c|}
\hline$\%$ & 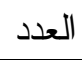 & أسباب إقامة المشرو عات & 8 \\
\hline$r \leq 6) \leq$ & $\checkmark$ & حاجة المنطقة & 1 \\
\hline $7 r_{6} \cdot V$ & 11 & تتاسب المكان لنوع المشروع & r \\
\hline$T_{6} \cdot V$ & 11 & سهولة نوزيع المنتج & r \\
\hline rv.9r & 11 & وفرة العمالة & $\varepsilon$ \\
\hline$v_{6} \ldots$ & r & وفرة المو اد الخام & $\circ$ \\
\hline
\end{tabular}

المصدر: جُمعت وحُببت من بيانات استمار ات الاسنيبان الميداني لعينة الدر اسة .

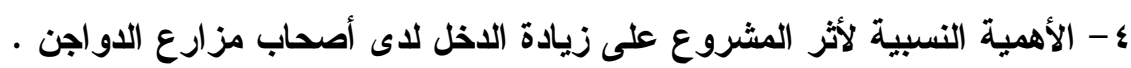

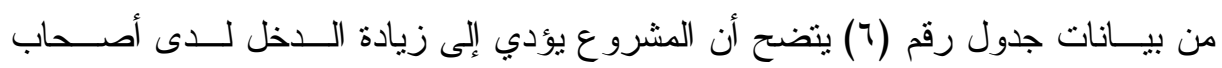

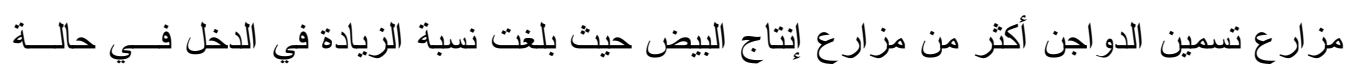

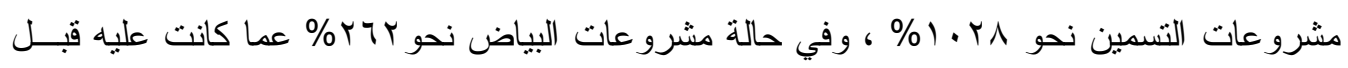

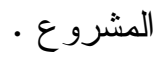
جدول رقم (ج): الأهية النسبية لأثر المشروع على زيادة الدخل لدي أصحاب مشروعات الدواجن في عينة الدر اسة بمحافظة الغربية عام ع ا ـ. ال.

\begin{tabular}{|c|c|c|c|c|c|c|c|c|c|c|}
\hline \multicolumn{9}{|c|}{ ألثُ الشُروع على زيادة: ذذل صادب المشروع } & \multirow{3}{*}{ 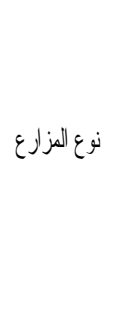 } & \multirow{3}{*}{ p } \\
\hline \multicolumn{4}{|c|}{ في مالة زيادة للذل } & \multirow{2}{*}{$\%$} & \multirow{2}{*}{ 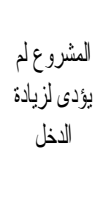 } & \multirow{2}{*}{$\%$} & \multirow{2}{*}{ لزيلة اللذل } & \multirow{2}{*}{ للززارع } & & \\
\hline نسبةً النغبر & (ألنق جنبر & 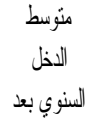 & السنو قلتل & & & & & & & \\
\hline $1 . r \wedge$ & riqru, & 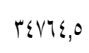 & $M A r \cdot, \lambda$ & $\mathrm{v}, \xi 1$ & r & $9 r, 09$ & ro & rv & تسمبن & 1 \\
\hline mir & $r .97,7$ & $r \wedge 94, Y$ & A.. & . & . & l.. & r & r & 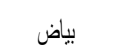 & r \\
\hline
\end{tabular}




\section{ه- الأهمية النسبية لأصحاب المشروع تبعاً لمستويات الدخل في عينة الدراسة .}

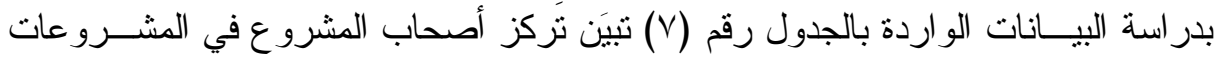

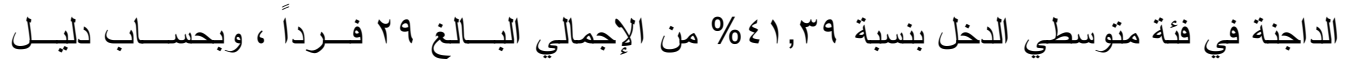

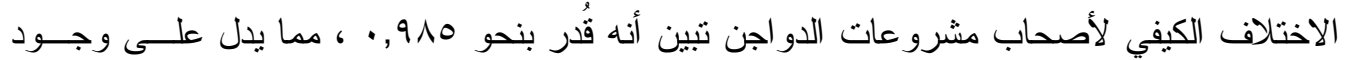

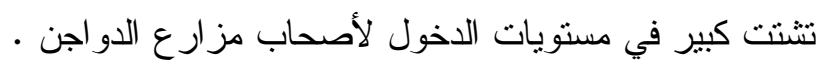

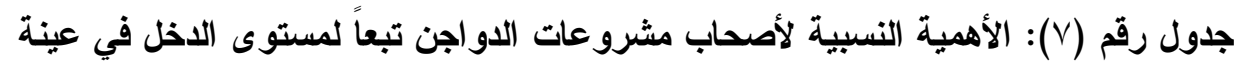

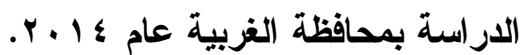

\begin{tabular}{|c|c|c|c|c|}
\hline دليل الاختلاف الكيفي & $\%$ & العدد العد & مستويات الدخل & r \\
\hline \multirow{4}{*}{$\cdot, 910$} & r., & 9 & محــــــدود & 1 \\
\hline & $\leqslant 1, \Gamma q$ & ir & مت متــــوسط & r \\
\hline & $r V, 09$ & $\wedge$ & مرتفة & r \\
\hline & $1 \ldots$ & rq & \multicolumn{2}{|l|}{ الإجمــــــالي } \\
\hline
\end{tabular}

المصدر: جُمعت وحُسبت من بيانات استمار ات الاستبيان الميداني لعينة الدراسة .

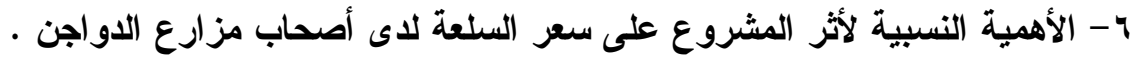

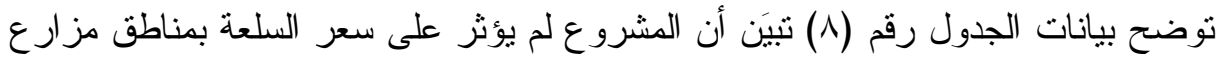

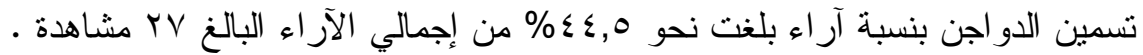

جدول رقم (^): الأهمية النسبية لأثر المشروع على سعر السلعة أو المنتج في منطقة المشروع بعينة

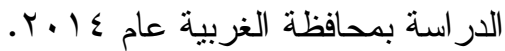

\begin{tabular}{|c|c|c|c|c|c|c|c|c|c|}
\hline \multicolumn{8}{|c|}{ درجة التأثز } & \multirow{3}{*}{ نوع المشروع } & \multirow{3}{*}{ 5 } \\
\hline \multirow{2}{*}{$\%$} & \multirow{2}{*}{ الإجمالي } & \multicolumn{2}{|c|}{ لم يتأثز سعر } & \multicolumn{2}{|c|}{ انخفاض سعر } & \multicolumn{2}{|c|}{ ارتفاع سعر } & & \\
\hline & & $\%$ & العدد & $\%$ & العدد & $\%$ & العد & & \\
\hline $1 \ldots$ & rV & $\varepsilon \varepsilon, 0$ & ir & $r, Y$ & 7 & r, & 9 & مز ارع تسمين & 1 \\
\hline $1 \ldots$ & r & $0 ., \cdot$ & 1 & $0 ., \cdot$ & 1 & . & . & مز ارع إنتاج & r \\
\hline
\end{tabular}

المصدر: جُمعت وحُسبت من بيانات استمار ات الاستبيان الميداني لعينة الدراسة .

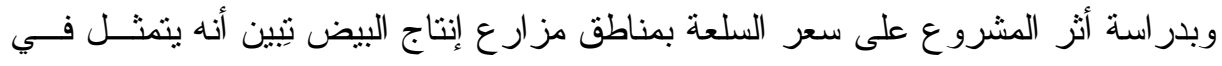

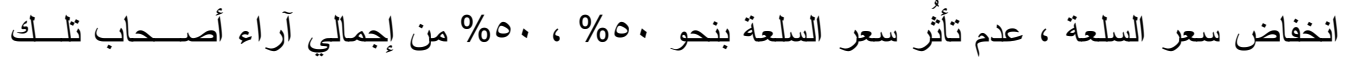

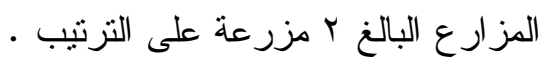

V - الأهمية النسبية لوعي أصحاب مشروعات الدواجن بالآثار الاقتصادية القومية .

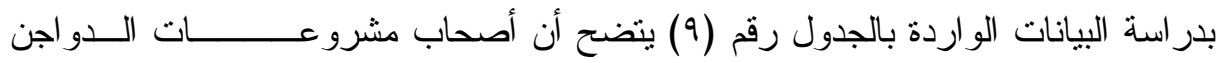

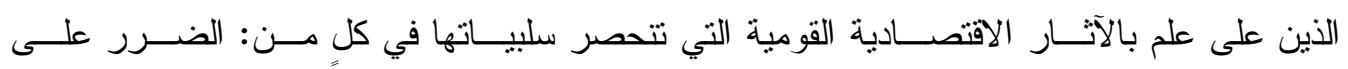

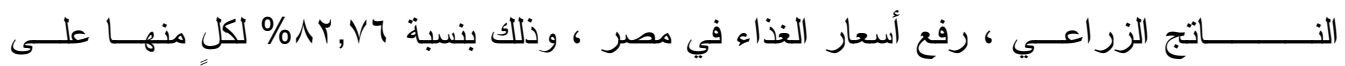




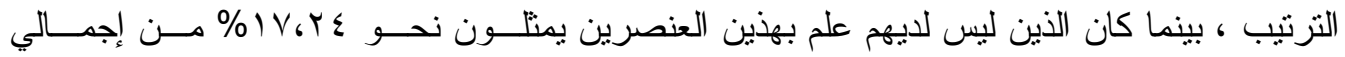

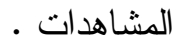
جدول رقم (9): الأهمية النسبية لوعي أصحاب مشروعات الدواجن بالآثار الاقتصادية القومية في

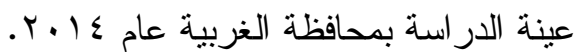

\begin{tabular}{|c|c|c|c|c|c|c|c|c|c|}
\hline \multicolumn{8}{|c|}{ مدى العلم } & \multirow{3}{*}{ الآثار الاقتصادية القومية } & \multirow{3}{*}{ e } \\
\hline \multicolumn{2}{|c|}{ الإجمالي } & \multirow{2}{*}{ للاختلان } & \multicolumn{2}{|c|}{$\gamma$} & \multirow{2}{*}{ الاختلاف } & \multicolumn{2}{|c|}{ نعم } & & \\
\hline$\%$ & العدد & & $\%$ & العد & & $\%$ & 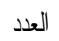 & & \\
\hline $1 .$. & rq & \multirow{4}{*}{ ، “99 } & $\mid V, Y \varepsilon$ & - & \multirow{4}{*}{$\cdot, 9 \wedge \Lambda$} & $\lambda r, Y \Psi$ & r६ & الضرر على الناتج الزر اعي & 1 \\
\hline $1 .$. & rq & & $\mid Y, Y \xi$ & 。 & & $\Delta r, Y r$ & $r \varepsilon$ & رفع أسعار الغذاء في مصر & r \\
\hline $1 .$. & rq & & $\varepsilon 1, r \wedge$ & rr & & $01, \pi$ & iv & حرمان الأفر اد من الطعام & r \\
\hline & AV & & & rr & & & 10 & الإجمالي & \\
\hline
\end{tabular}

المصدر: جُمعت وحُسبت من بيانات استمارات الاستنيان الميداني لعينة الدراسة .

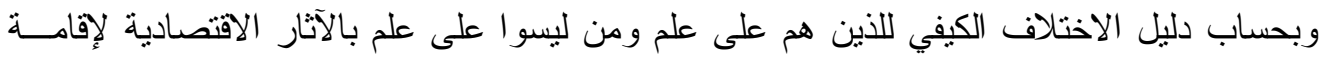

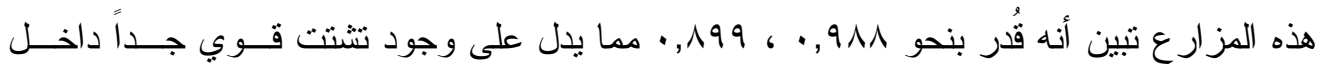

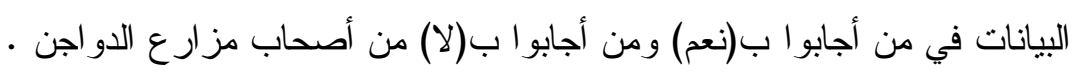

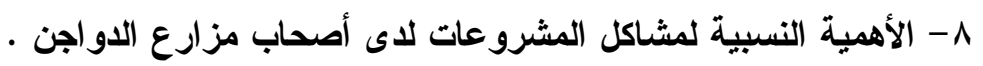

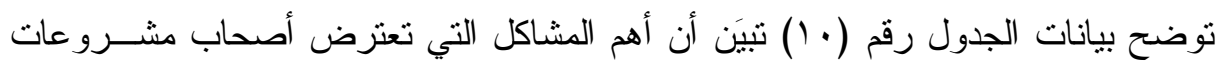

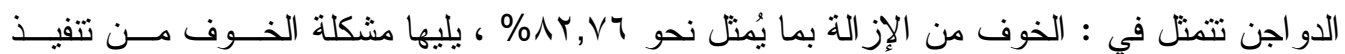

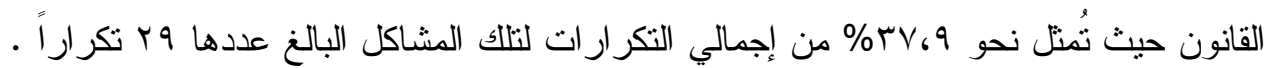
جدول رقم ( • (): الأهمية النسبية لمشاكل المشروعات لاي أصحاب مشروعات الدواجن في عينة

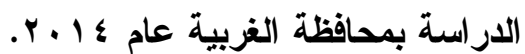

\begin{tabular}{|c|c|c|c|c|}
\hline دليل الاختلاف & \% من إجمالي المشاهدات & العدد العد & مشاكل المشروعات & 5 \\
\hline \multirow{5}{*}{$\cdot, \wedge \varepsilon 1$} & r & 9 & عدم تو افر العمالة & 1 \\
\hline & $\Lambda r, V T$ & $r \varepsilon$ & الخوف من الإز الة & r \\
\hline & 7,9 . & r & صعوبة تصريف المنتج & $r$ \\
\hline & $r v, q \mu$ & 11 & الخوف من تتفيذ القانون & $\varepsilon$ \\
\hline & & $r q$ & \multicolumn{2}{|l|}{ إجمالي عدد المشاهدات } \\
\hline
\end{tabular}

المصدر: جُمعت وحُسبت من بيانات استمارات الاستيان الميداني لعينة الدراسة .

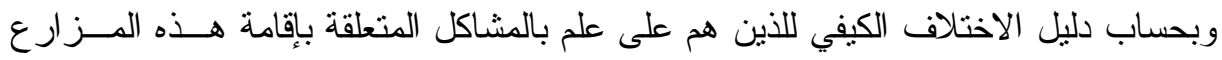

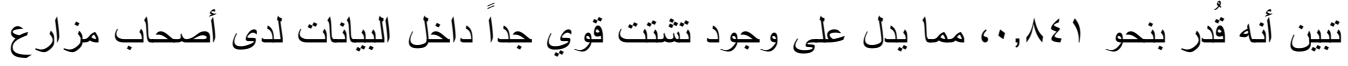

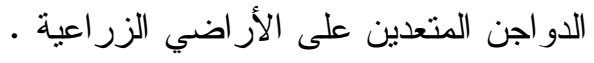




\section{ثانياً: مشروعات تسمين الماشية:}

يتتاول هذا الجزء من البحث بعض الخصائص الاجتماعية والاقتصادية لأصحاب الأراضي

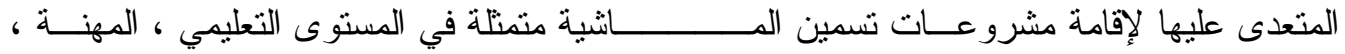

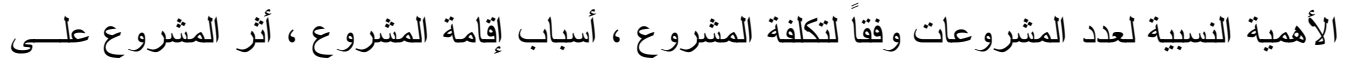

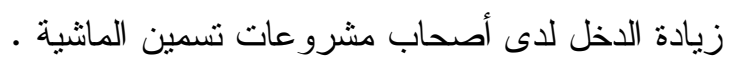

1- الأهمية النسبية لبعض الخصائص الاجتماعية لأصحاب مشروعات تسمين الماثية .

بدر اسة البيانات الواردة بالجدول رقم (1) (1) تنبين تركز معظم أصحاب مشروعات تسمين

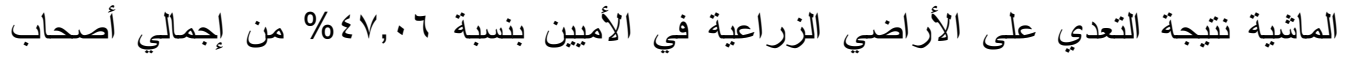

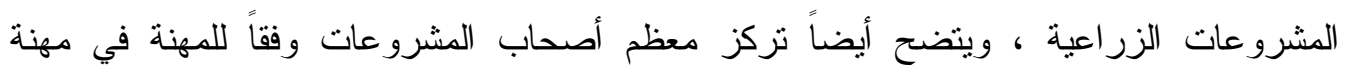

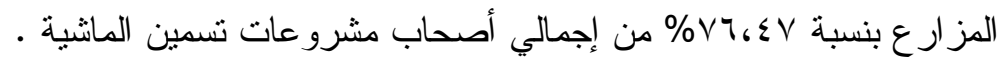
جدول رقم (1 (1): الأهمية النسبية لبعض الخصائص الاجتماعية لأصحاب مشروعات مزارعة لنمين

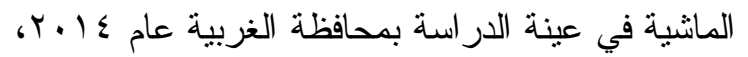

\begin{tabular}{|c|c|c|c|c|c|}
\hline \multicolumn{3}{|c|}{ المؤشر ات الإحصائية لأصحاب مشروعات تسمين الماثية } & \multirow{2}{*}{ البيان } & & \\
\hline دليل الاختلاف الكيفي & $\%$ & العدد = بq & & & $?$ \\
\hline \multirow{5}{*}{$\cdot, \wedge \vee \varepsilon$} & $\leq V, \cdot 7$ & $\wedge$ & أمى & \multirow{5}{*}{ 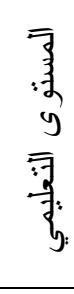 } & 1 \\
\hline & $1 v, 70$ & r & يقر أ ويكتب & & r \\
\hline & $0, \wedge \wedge$ & 1 & تعليم أساسى & & r \\
\hline & 11,87 & r & مؤ هل متوسط & & $\varepsilon$ \\
\hline & $1 v, 70$ & $r$ & مؤ هل جامعى & & 0 \\
\hline \multirow{3}{*}{$\cdot, 0 \leqslant$} & $\vee\urcorner, \Sigma V$ & ir & 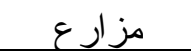 & \multirow{3}{*}{$\bar{q}$} & 1 \\
\hline & . & - & موظف & & $r$ \\
\hline & rr,or & $\varepsilon$ & أعمال حرة & & $r$ \\
\hline
\end{tabular}

المصدر: جُمعت وحُسبت من بيانات استمار ات الاستنبيان الميداني لعينة الدراسة .

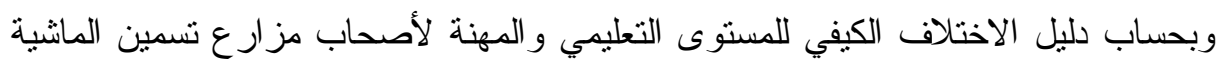

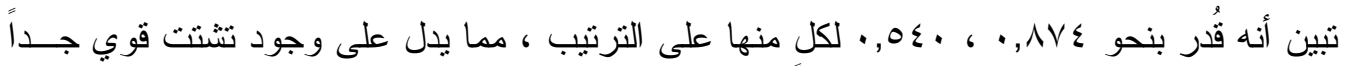

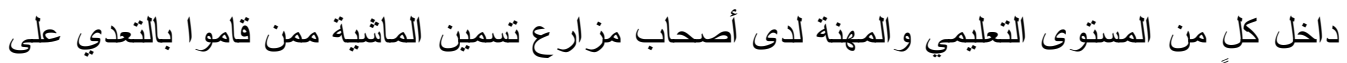
الأر اضي الزر اعية . الأبن

r - الأهمية النسبية لعدد المشروعات وفقاً لتكلفة المشروع لأصحاب مزارع تسمين الماثية

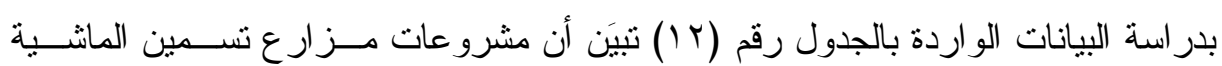

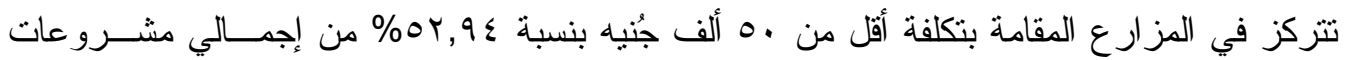

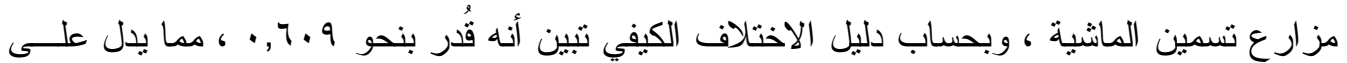
وجود تشتت قوي بين تكلفة مز ارع تسمين الماثشية بعينة الدراسة . 
جدول رقم (Y (1): الأهمية النسبية لعدد المشروعات وفقاً لتكلفة مشروعات تسمين الماشية في عينة

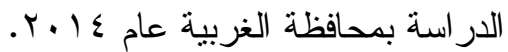

\begin{tabular}{|c|c|c|c|c|c|c|c|c|c|}
\hline \multicolumn{3}{|c|}{ الإجمالي } & \multicolumn{6}{|c|}{ فئات تكلفة المشروعات } & \multirow{3}{*}{ المشروع } \\
\hline \multirow{2}{*}{ الاختّلاف } & \multirow{2}{*}{ إلنسب } & \multirow{2}{*}{ الجمالي عدد } & \multicolumn{2}{|c|}{ فأكثر } & \multicolumn{2}{|c|}{. 0 > . 1 ألف جنبه } & \multicolumn{2}{|c|}{ أقل من •.0 ألف } & \\
\hline & & & $\%$ & العدد - العد & $\%$ & 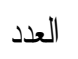 & $\%$ & العدد العد & \\
\hline$\cdot, 7.9$ & $1 \ldots$ & IV & YT,OH & $\varepsilon$ & rT, Or & $\varepsilon$ & Or, $9 \leqslant$ & 9 & تلسمين \\
\hline
\end{tabular}

المصدر: جُمعت وحُسبت من بيانات استمار ات الاستبيان الميداني لعينة الدراسة .

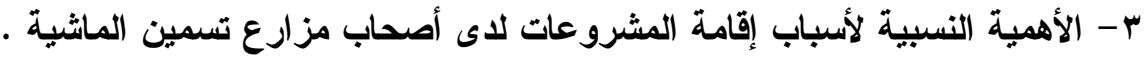

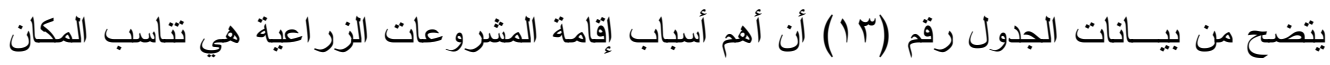

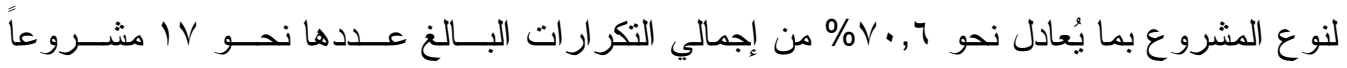

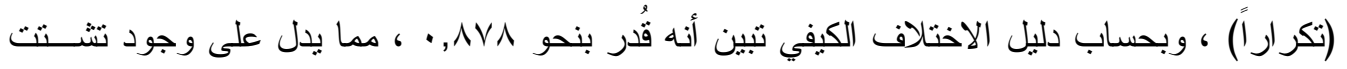

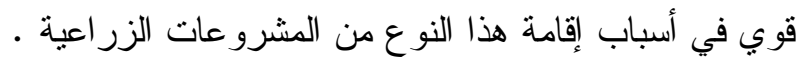

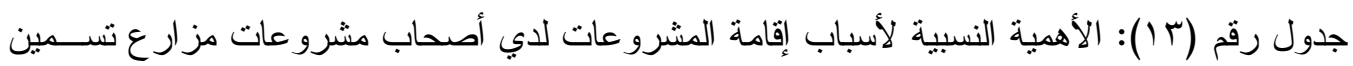

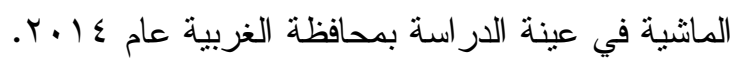

\begin{tabular}{|c|c|c|c|c|}
\hline دليل الاختلاف الكيفي & $\%$ & العدد (التكر ار) & أسباب إقامة المشروعات & 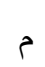 \\
\hline \multirow{5}{*}{$\cdot, \wedge \vee \wedge$} & ro, r & 7 & حاجة المنطقة للمشروع & 1 \\
\hline & $v \cdot, r$ & ir & تتاسب المكان لنوع & r \\
\hline & $1 V, T$ & r & سهولة توزيع المنتج & r \\
\hline & $\varepsilon \vee, 1$ & $\wedge$ & وفرة العمالة & $\varepsilon$ \\
\hline & or, 9 & 9 & وفرة المو اد الخام & 0 \\
\hline
\end{tabular}

المصدر: جُمت وحُسبت من بيانات استمار ات الاستيان الميداني لعينة الدراسة .

ع - الأهمية النسبية لأثر المشروع على زيادة الاخل لدى أصحاب مشروعات تسمين الماثية.

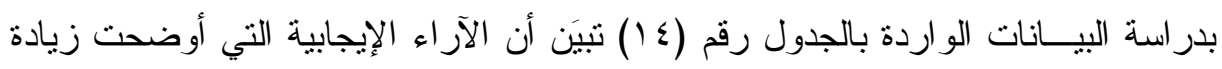

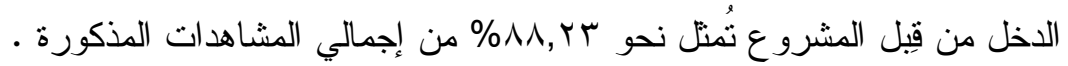


جدول رقم (ع (): الأهمية النسبية لأثر المشروع على زيادة الدخل لدي أصحاب مشروعات ثــمين الماثية في عينة الدراسة بمحافظة الغربية عام عـ ا.ب.

\begin{tabular}{|c|c|c|c|c|c|c|c|c|c|c|}
\hline \multicolumn{10}{|c|}{ أنُز الشُروع على زيلاة دذل صادب الشُروع } & \multirow{3}{*}{ لششروع } \\
\hline \multicolumn{4}{|c|}{ في حالة زيادة اللذل } & \multirow[b]{2}{*}{$\%$} & \multirow[b]{2}{*}{ الششاهاتي } & \multirow[b]{2}{*}{$\%$} & \multirow[b]{2}{*}{ 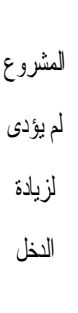 } & \multirow[b]{2}{*}{$\%$} & \multirow[b]{2}{*}{ 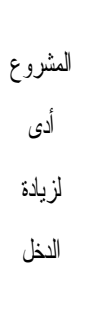 } & \\
\hline معلى النيز & ألنغير & منوسط اللنّل & اللمنو اللنّل & & & & & & & \\
\hline AIV & $r 4,04$ & $\{1, \cdot \cdot$ & $\xi, \xi \vee ।$ & 1.. & iv & 11,194 & r & $\Lambda,, Y \mu$ & 10 & تسمينة \\
\hline
\end{tabular}

المصدر: جُمتت وحُسبت من بيانات استمار ات الاستيبان الميداني لعينة الدراسة .

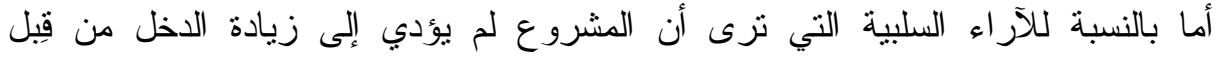

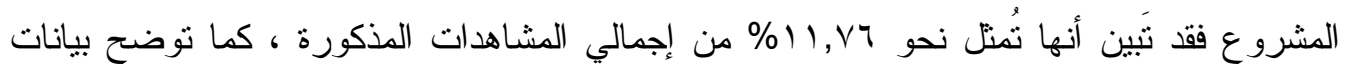

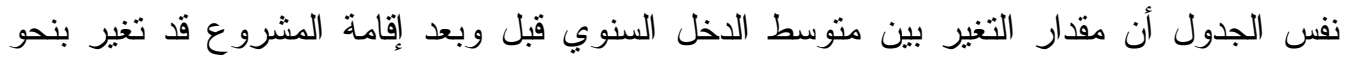

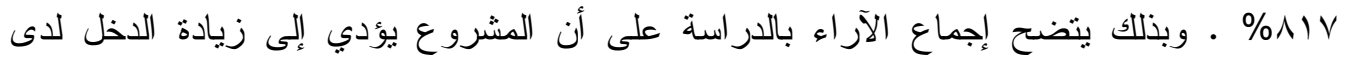

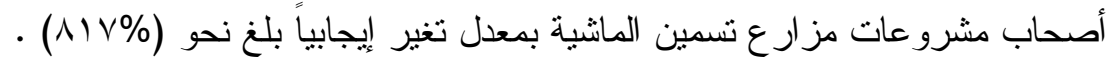

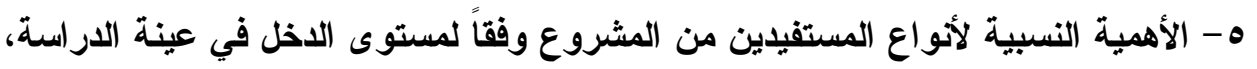

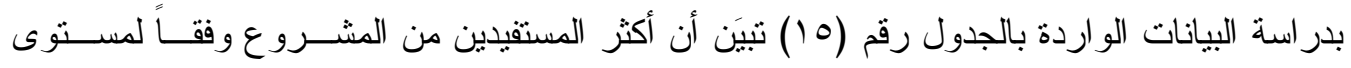

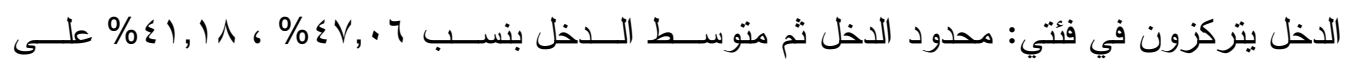
الترنيب من إجمالي المستقيدين البالغ عددهم V V فرداً على الترنيب ، وبحساب دليل الاختلاف الكيفي

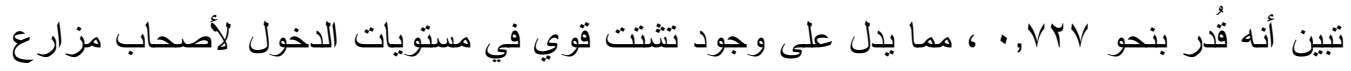
تسمين الماثية . جدول رقم (10): الأهمية النسبية لأنواع المستفيدين من أصحاب مشروعات تسمين الماثية تبعـاً

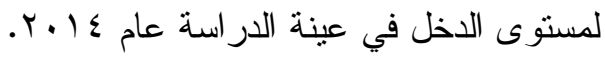

\begin{tabular}{|c|c|c|c|c|}
\hline دليل الاختلاف الكيفي & $\%$ & 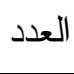 & مستوى الدخل & r \\
\hline \multirow{4}{*}{$\cdot, V Y V$} & $\varepsilon V, \cdot T$ & $\wedge$ & محــــــدود & 1 \\
\hline & $\leqslant 1,1 \wedge$ & V & مت تـــــوسط & $r$ \\
\hline & $11, V_{7}$ & r & مرتفـــــع & $r$ \\
\hline & $1 \ldots$ & IV & \multicolumn{2}{|l|}{ الإجمالي } \\
\hline
\end{tabular}

المصدر: جُمعت وحُسبت من بيانات استمار ات الاستنبيان الميداني لعينة الدر اسة . 
ج- الأهمية النسبية لأثر المشروع على سعر السلعة لاى أصحاب مشروعات تسمين الماثية

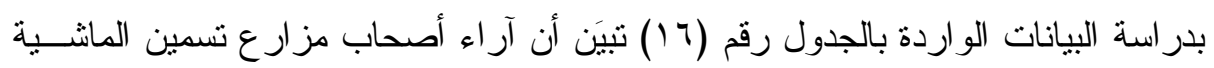

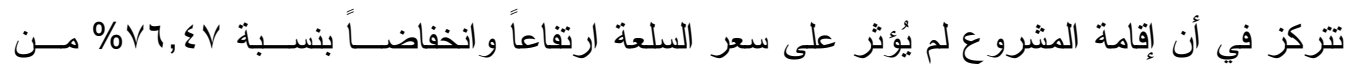

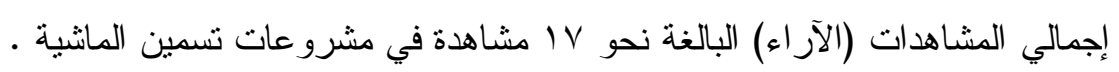

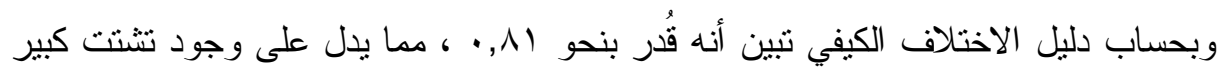

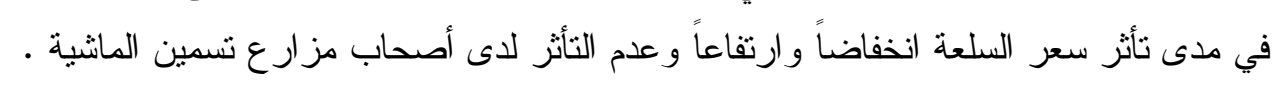
جدول رقم (7 ()): أثز المشروع على سعر السلعة أو المنتج لدي أصحاب مشروعات تسمين الماشية

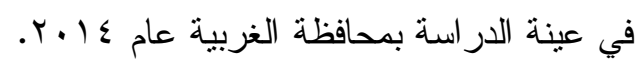

\begin{tabular}{|c|c|c|c|c|c|c|c|c|c|}
\hline \multicolumn{9}{|c|}{ تأثز سعر السلعة } & \multirow{3}{*}{ المشروع } \\
\hline \multirow{2}{*}{ الاختيلاف } & \multirow{2}{*}{$\%$} & \multirow{2}{*}{ الإجمالي } & \multicolumn{2}{|c|}{ سعر الملثعة } & \multicolumn{2}{|c|}{ سعر السلعة } & \multicolumn{2}{|c|}{ سعر السلعة } & \\
\hline & & & $\%$ & العدد & $\%$ & العدد & $\%$ & العدد & \\
\hline$\cdot, \Lambda 1$. & $1 \ldots$ & IV & $V \Psi, \leqslant V$ & 14 & $1 V, 70$ & r & $0, \Lambda \Lambda$ & 1 & تسمين المانشية \\
\hline
\end{tabular}

المصدر: جُمت وحُسبت من بيانات استمارات الاستيان الميداني لعينة الدراسة .

V-الأهمية النسبية لوعي أصحاب مشروعات تسمين الماثية بالآثار الاقتصادية القومية .

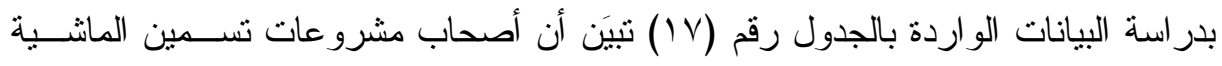
لديهم الوعي بالآثار الاقتصادية القومية منتكلة في : الضرر على الناتج الزراعي ، بلى رفع أسعار الغذاء

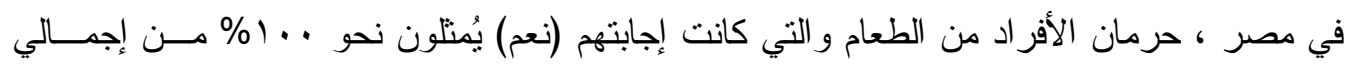

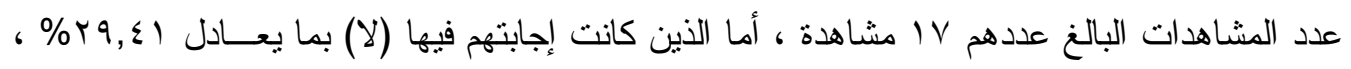

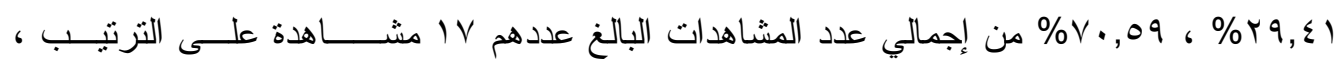

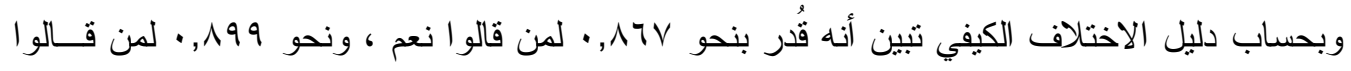

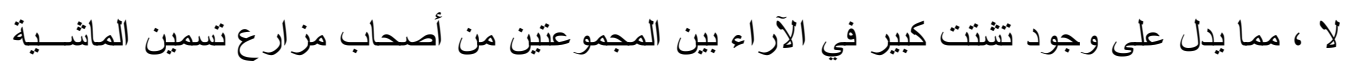

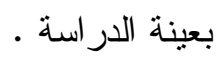


جدول رقم (V) ( V): الأهمية النسبية لوعي أصحاب مشروعات تشمين الماثـــية بالآتـار الاقتصــادية

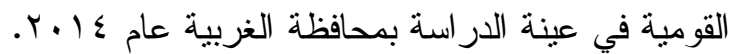

\begin{tabular}{|c|c|c|c|c|c|c|c|}
\hline \multicolumn{6}{|c|}{ مدى العلم } & \multirow[b]{2}{*}{ الآثار الاقتصادية } & \multirow[b]{2}{*}{ r } \\
\hline الاختيلاف & $\%$ & العدد (لا) & الاختلاف & $\%$ & ( العدد & & \\
\hline \multirow{3}{*}{$\cdot, \wedge 99$} & $r q, \S)$ & 0 & \multirow{3}{*}{. ‘NTV } & $1 \ldots$ & IV & الضرر على الناتج & 1 \\
\hline & $r q, \varepsilon)$ & 0 & & $1 \ldots$ & IV & رفع أسعار الغذاء & r \\
\hline & $V_{\cdot}, 09$ & ir & & $1 \ldots$ & iv & حرمان الأفر اد من الطعام & r \\
\hline
\end{tabular}

المصدر: جُمت وحُسبت من بيانات استمار ات الاستبيان الميداني لعينة الدراسة .

1- الأهمية النسبية لمشاكل المشروعات لاى أصحاب مشروعات تسمين الماثية .

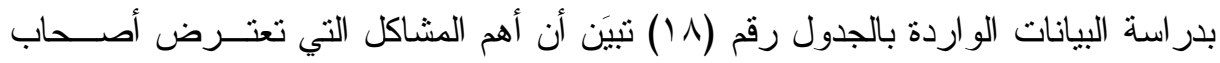

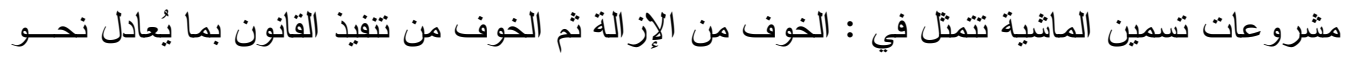

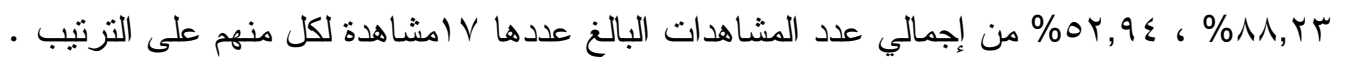

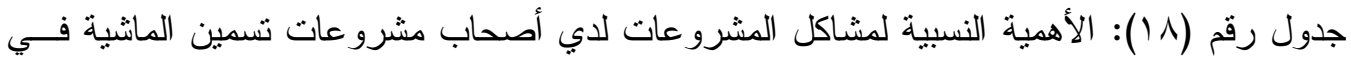

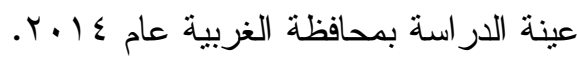

\begin{tabular}{|c|c|c|c|c|}
\hline دليل الاختلاف الكيفي & $\%$ & العدد (تكرار ) & مشاكل المشروعات & s \\
\hline \multirow{4}{*}{$\cdot, \wedge) \mathrm{V}$} & $1 V, \tau \leq$ & r & عدم تو افر العمالة & 1 \\
\hline & $\Lambda \Lambda, Y \mu$ & 10 & الخوف من الإز الة & r \\
\hline & صفر & صفر & صعوبة تصريف المنتج & r \\
\hline & or, $9 \leq$ & 9 & الخوف من تتفيذ القانون & $\varepsilon$ \\
\hline
\end{tabular}

المصدر: جُمعت وحُسبت من بيانات استمار ات الاستبيان الميداني لعينة الدراسة .

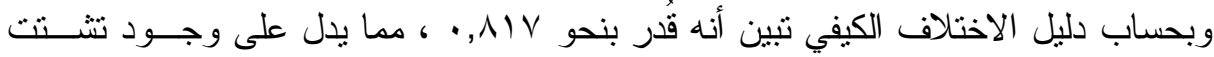

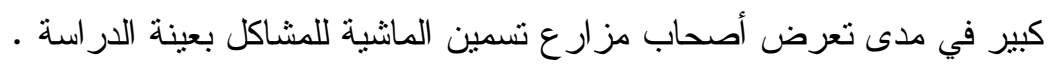

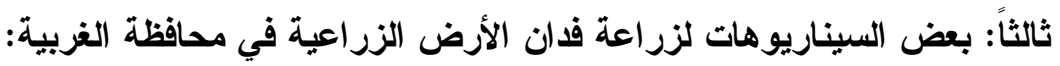

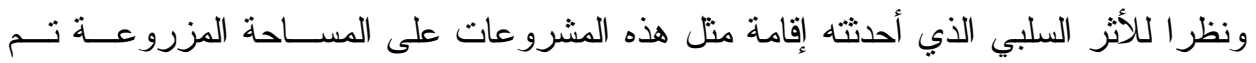

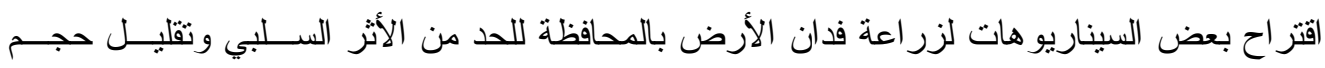

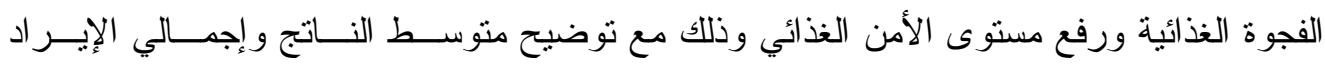
و التكاليف الكلية وصافي العائد الفداني كما يلي: 
- الأول: البرسيم التحريش يعقبه قطن : توضح بيانات جدول رقم (9 (1) أن متوسط إنتاج الفــدان

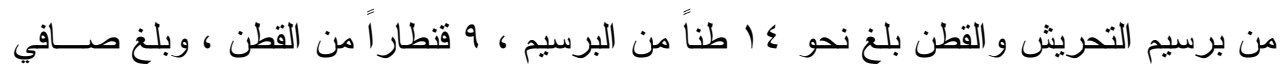

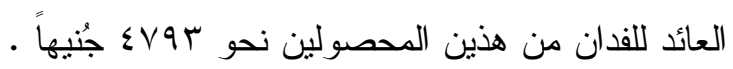

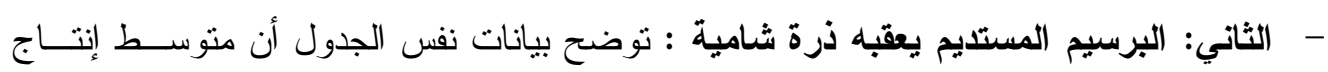

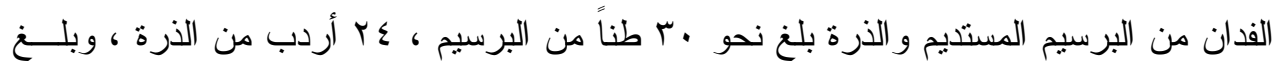

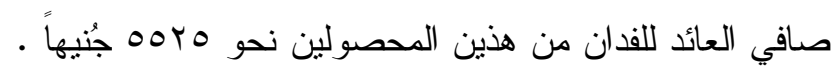

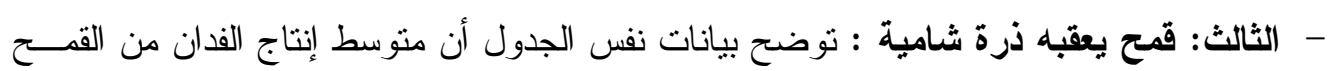

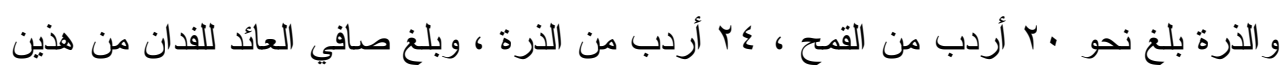

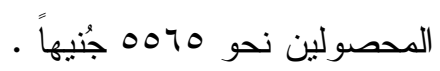
- الر ابع: البرسيم المستديم يعقبه أرز : توضح بيانات نفس الجدول أن متوسط إنتاج الفدان مــن

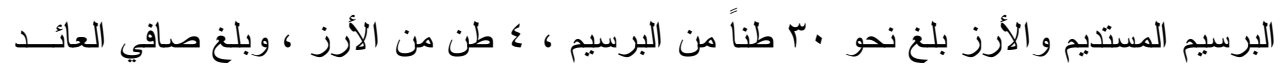

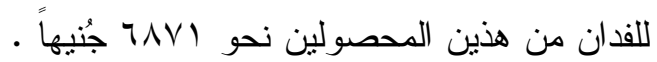
جدول رقم (9 (1): منوسط إنتاج وتكاليف وصافي العائد للفدان من بعض المحاصيل الزر اعية

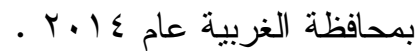

\begin{tabular}{|c|c|c|c|c|c|c|}
\hline صافي العائد & الفالنكاليف & إلجمالي & متوسط الإنتاج & الوحدة & المحصول & 5 \\
\hline r9o. & 0.0 & $9 \ldots$ & r. & طن & البرسيم المستديم & 1 \\
\hline $11 \ldots$ & M... & $\varepsilon r \ldots$ & $1 \varepsilon$ & طن & البرسيم التحريش & r \\
\hline ५ १. & 001. & $90 \ldots$ & $r$. & أردب & القمح & r \\
\hline rqY & 0199 & NIr. & $\varepsilon$ & طن & الأرز & $\varepsilon$ \\
\hline 1. & lorv. & roo.. & iv & طن & بطاطس & 0 \\
\hline 10V0 & $\leqslant 970$ & $70 \leq$. & $r \leqslant$ & أردب & الذرة & 7 \\
\hline $1 \leqslant Y \wedge r$ & Ar\^ & rro.. & 10 & طن & الطماطح & $\checkmark$ \\
\hline r & N1OV & 1110. & 9 & قنطار & قطن & $\wedge$ \\
\hline
\end{tabular}

المصدر : مديرية الزر اعة بالغربية- سجلات إدارة الإحصاء - بيانات غير منثورة - عام ع ا.ب ـ. 
- الخامس: قمـح يعقبه أرز: توضح بيانات نفس الجدول أن متوسط إنتاج الفدان من القمح والأرز

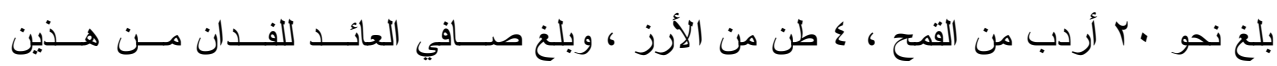

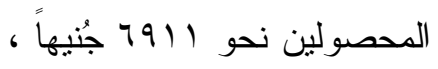

- السادس: برسيم تحريش يعقبه بطاطس ثم ذرة شامية : نوضح بيانات نفس الجدول أن متوسط

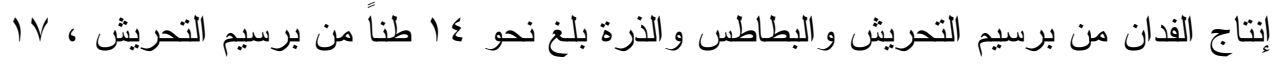

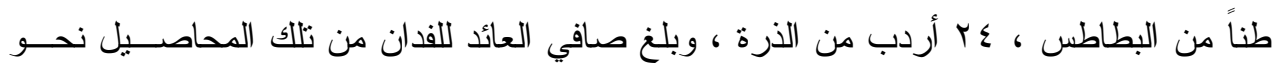

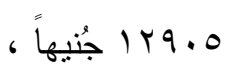
- السابع: برسيم تحريش يعقبه بطاطس ثم أرز: توضح بيانات نفس الجدول أن متوســـ إنتــاج

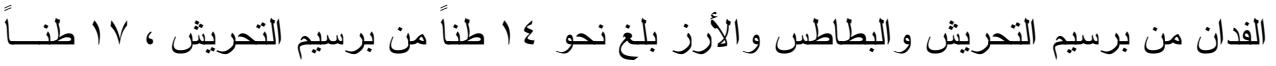

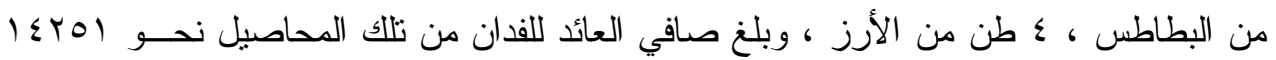
جُنيهاًً . من البط.

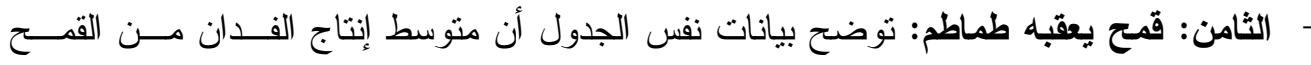

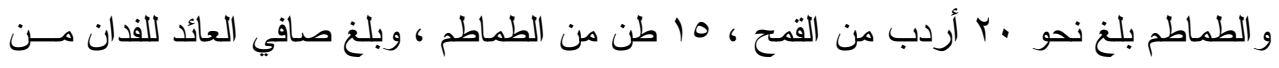
هذين المحصولين نحو MYVT

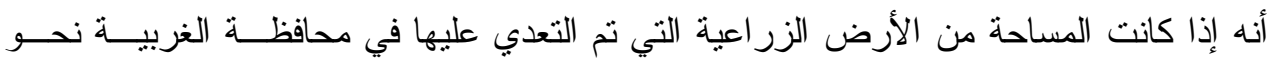

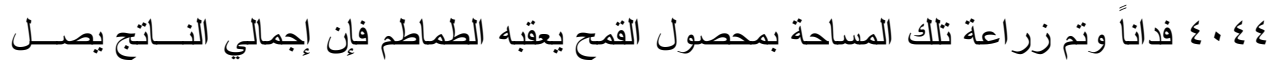

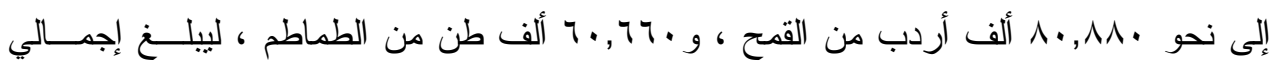

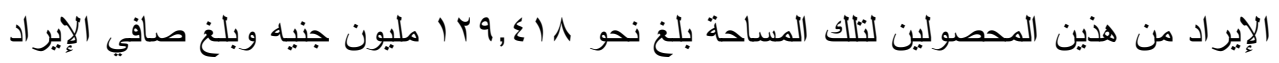

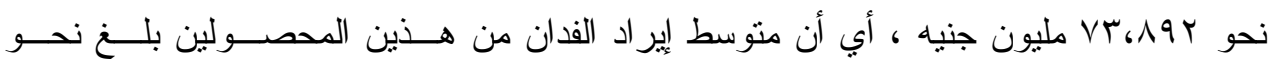

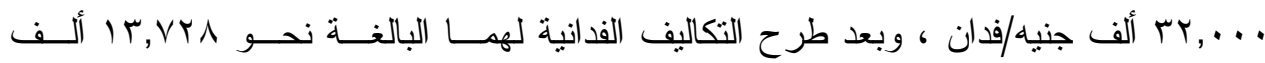

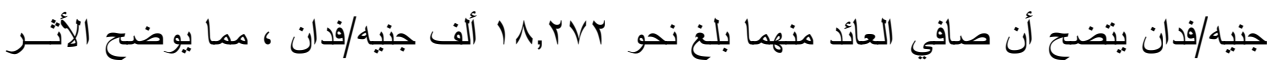

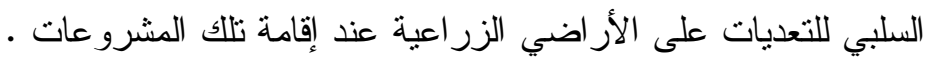

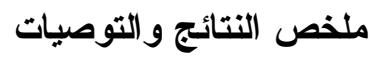

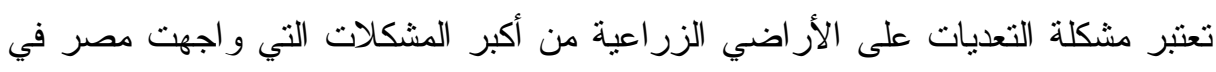

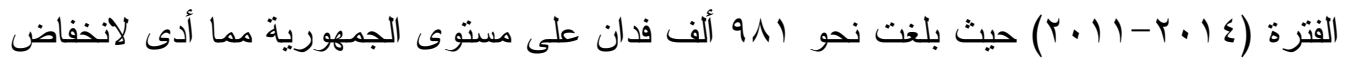

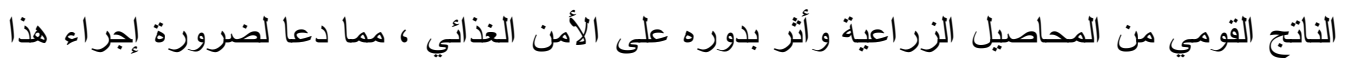
البحث للتعرف على الآثار الاقتصادية والاجتماعية المصاحبة لتلك الظاهرة من خلال بيانات أولية تم

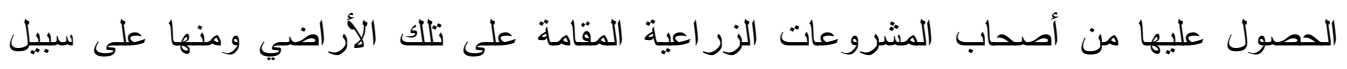
المثال لا الحصر : أصحاب مشروعات مزارع الدواجن و أصحاب مشروعات نسمين الماشية وقد

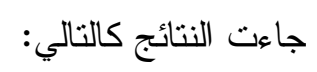

أولاً: بالنسبة لأصحاب مشروعات مزارع الدار الداجن:

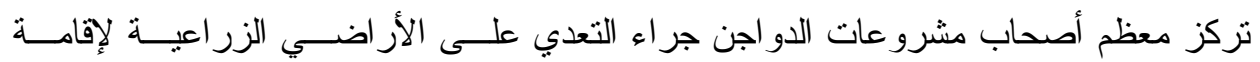

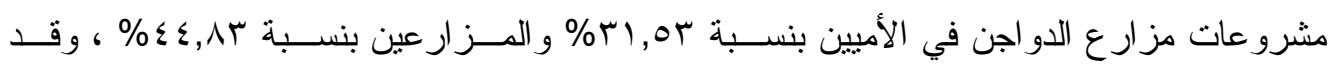




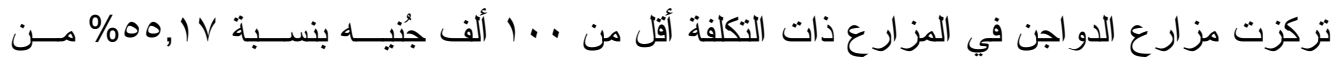

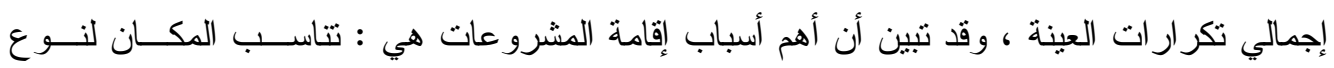

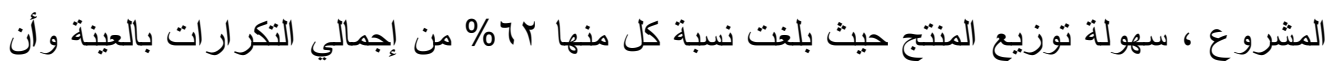

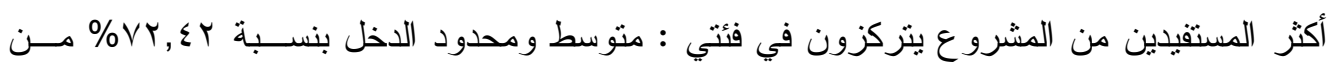

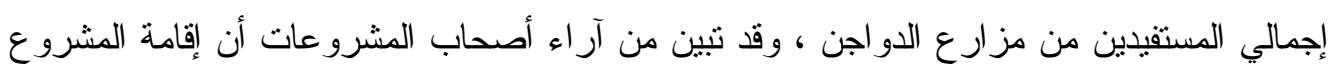

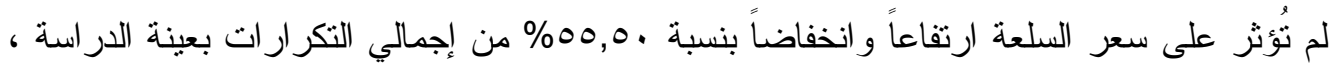

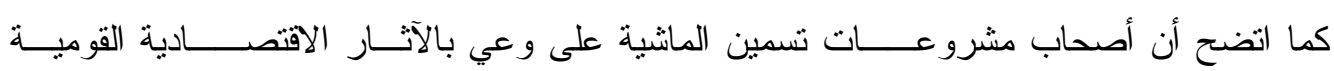

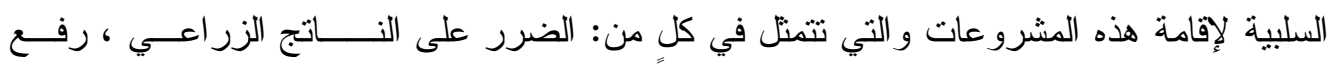

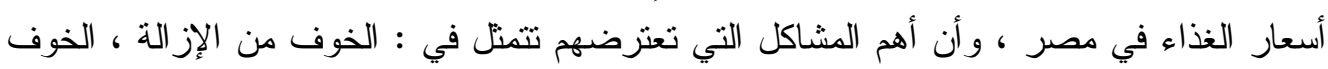
من تتفيذ القانون على الترتيب .

\section{ثانياً: بالنسبة لأصحاب مشروعات تسمين الماثية:}

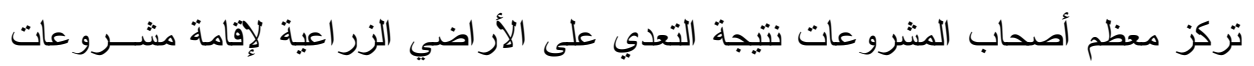

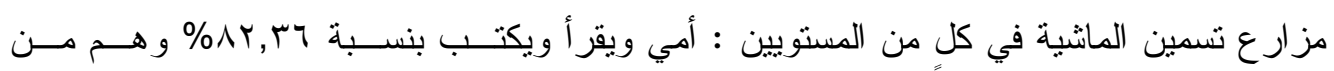

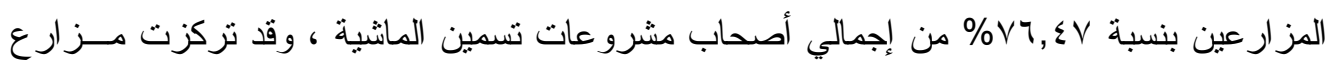

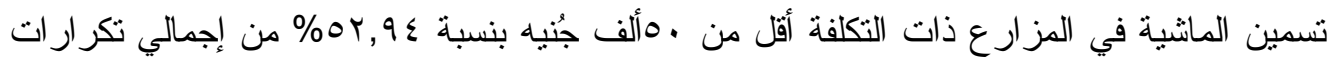
العينة ، وأن أهم أسباب إقامة المشروعات هي : تتاسب المكان لنوع المشروع ، و ووفرة المو اد الخام

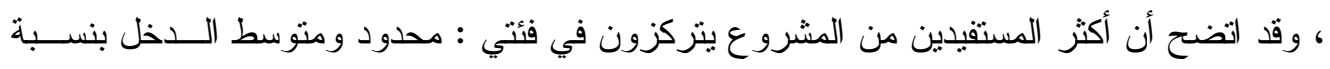

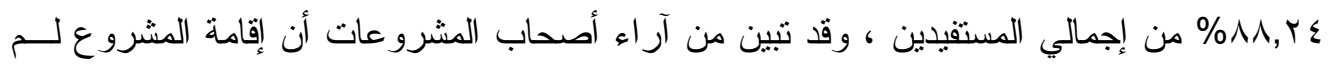

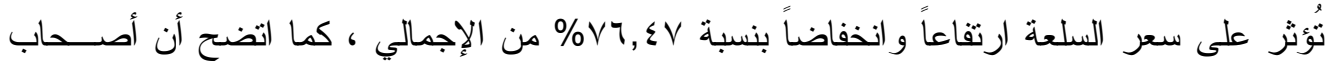

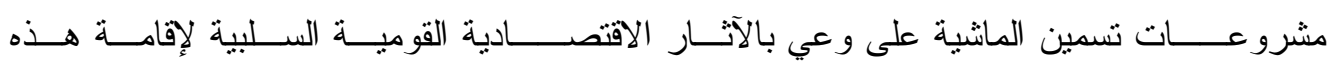

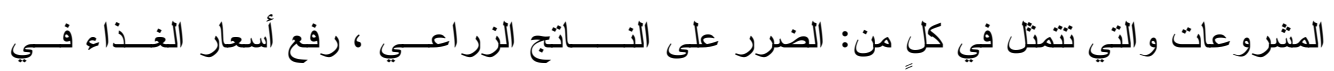

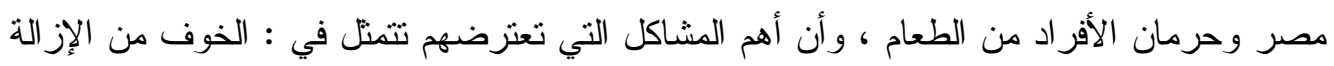

$$
\text { ، الخوف من تتفيذ القانون على الترتيب . }
$$

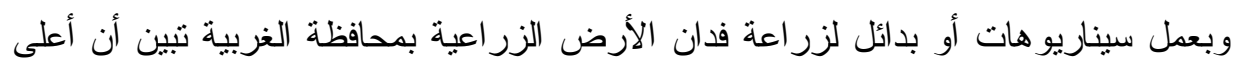

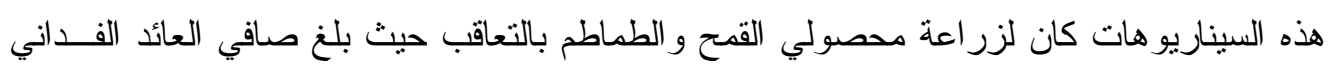

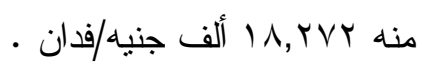

\section{التوصيات}

( ) فرض عقوبات وغرامات كبيرة على المتز يتحملها كلٍ من البائع و المشتري مناصفة وتقوم

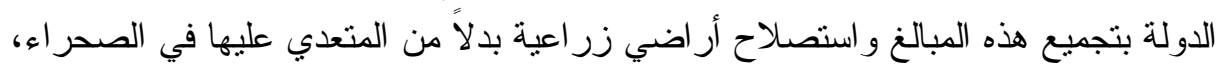

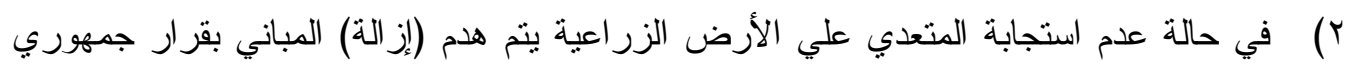
علي نفقة المتعدي .

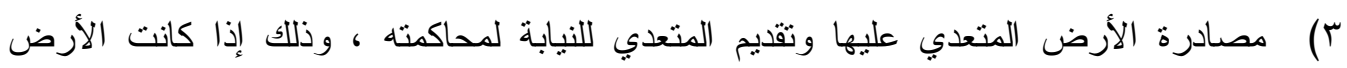

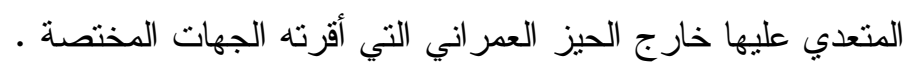




\section{المراجع}

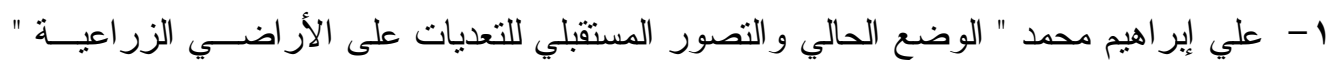

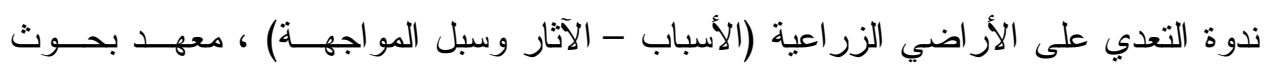

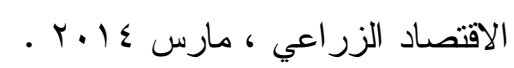

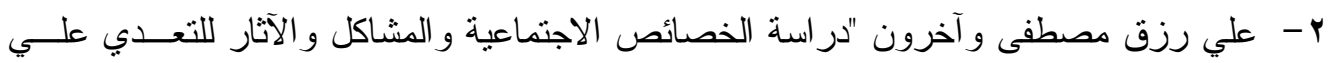

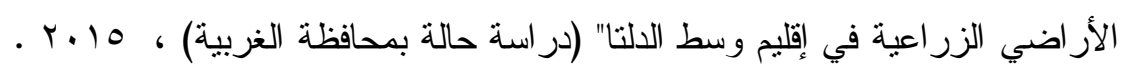

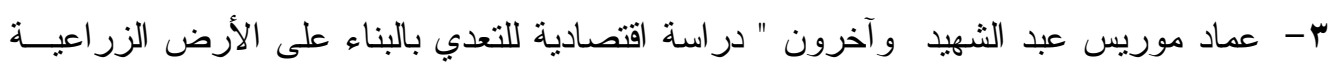

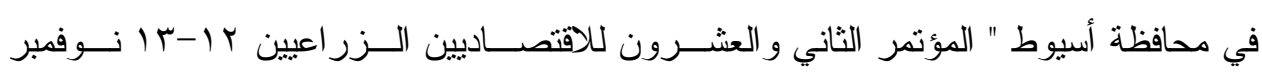
.r. I

ع - محدد صلاح الدين الجندي و آخرون " تحليل قياسي لكفاءة استخدم الموارد الزر اعية ودورهـــا

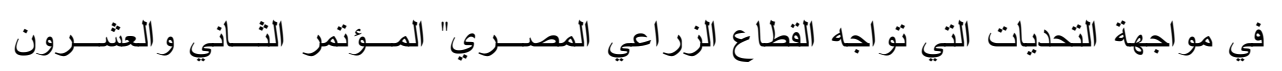

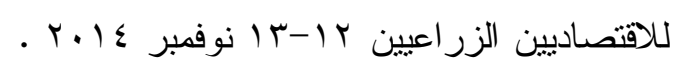

ه - سجلات إدارة الإحصاءات الزر اعية ، الشئون الزر اعية ، مديرية الزر اعة باعين بالغربية ، بيانــات 